\title{
The Reality of Financial Corruption in Kuwait: A Procedure Research According to Corruption Perception Index \& Related Rules
}

Melfi Muhammed Al Azemi

Ministers Council,

Kuwait.

Email: wstead@live.com

\section{Abdel Majeed Al Omari}

International Islamic University Malaysia,

Malaysia.

Email: alamri@iium.edu.my

Tawfeeq Al Omrani

International Islamic University Malaysia,

Malaysia.

Received February, 2019; Accepted May, 2019

\begin{abstract}
The study aimed at highlighting the reality of financial corruption in accordance with the corruption perception index and some other related rules in the state of Kuwait. The study covered the international and local reports showing the levels of financial corruption in Kuwait and its impacts on the economic development within the period from 2003 to 2019. The results indicated that there is a high indicator of financial corruption in the State of Kuwait that started to increase during the last ten years in all of it aspects including issue of money laundering, bypasses, manipulating the money of sovereign fund to invest in suspicious projects, the real-estate swindle, issues related to investing the money of the Public Institution of Social Insurance (retirement sums) and so on. The researchers got to a group of recommendations and proposals in both penal and Shariaa sides including activating the religious speech in all types of media, tribunes of mosques as well as all religious institutions about the danger of financial corruption on individual and society. It is also by warning people about out God punishment against every spoiler, activating the role of religion members in all attempts of government to fight the financial corruption phenomenon in the state with definitely adherence to the Islamic law principles in all financial issues of the state, agreements and so on. Moreover, it is very necessary to activate the most extreme laws and penalties against perpetrators of financial corruption without and exception.
\end{abstract}

Keywords: Financial Corruption; Corruption Perception Index.

Type: Research paper

This work is licensed under a Creative Commons Attribution 4.0 International License.

\section{DOI: 10.51325/ijbeg.v2i2.52}

\section{واقع الفساد المالي في الكويت دراسة إجرائية وفق مؤشر الفساد العالمي والقوانين ذات الصلة}

$$
\text { ملخص الدراسة }
$$


والتجاوزات والتلاعب بأموال الصندوق السيادي للإستثمار في مشاريع مشبوهة، والنصب العقاري على المواطنين، قضايا

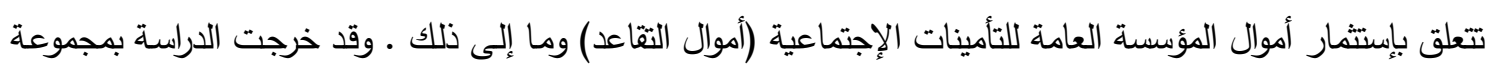
من التوصيات والمقترحات على الصعيدين الجزائي والثرعي منها تفعيل الخطاب الديني في كافة وسائل الإعلام والمنابر بالمساجد والمؤسسات الدينية حول خطورة الفساد المالي على الفرد والمجتمع وتحذير الناس من عقوبة الله بحق كل مفسدي، وتغعيل دور رجال الدين والاستعانة بهم في كل محاولات ومساعي الحكومة للتصدي لظاهرة تفشي الفساد المالي في

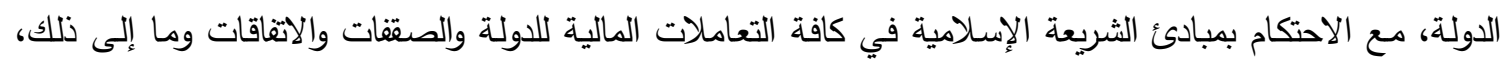
بالإضافة إلى تفعيل أقصى القوانين والعقوبات ضد مرتكبي قضايا الفساد المالي والحزم في تطبيقها على الجميع دون

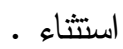
الكلمات الدالة: الفساد المالي، مؤشر الفساد العالمي •

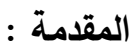

وضع على الصعيد الدولي مؤشرات تتبت وجود الفساد من عدمه، حيث ظهر لأول مرة هذا المؤشر سنة

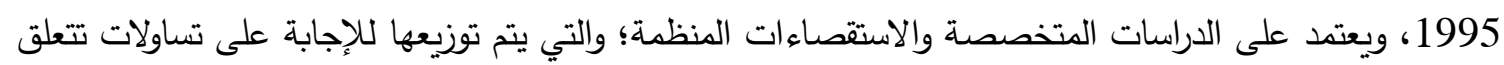
بالرشوة بالقطاع العام، والصفقات العمومية، والمشتريات الحكومية، واختلادس الأموال العامة وكذلك عن كفاءة

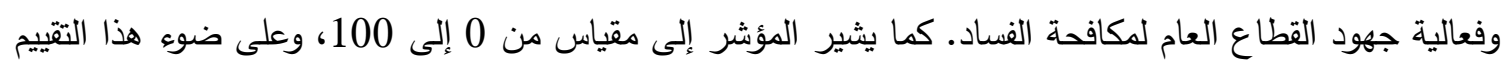
يتم ترتيب الدول في المؤشر تتازليا وفقا لمجموع النقط، حيث تعادل الدرجة 0 أعلى مستوى من مستويات الفساد

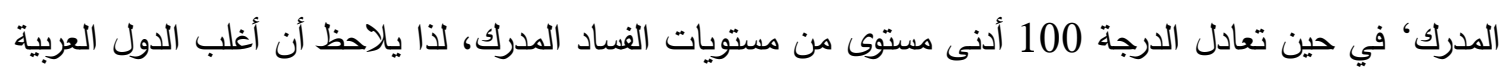
ترتيبها في النصف السفلي للمؤشره وبتقاط أقل من 40 ٪ وقد أشار تقرير منظمة الثفافية الدولية إلى أن الرشوة والمحسوبية والواسطة مرسخة بعمق في الحياة اليومية لتلك الدول، حتى أن قوانين مكافحة الفساد الموجودة ليس لها لها تأثير يذكر (بحار ، 2016).

حيث يتضمن المؤشر الثفافية والمساءلة، وتضارب المصالح، وتحويل الأموال، والبيروقراطية المفرطة،

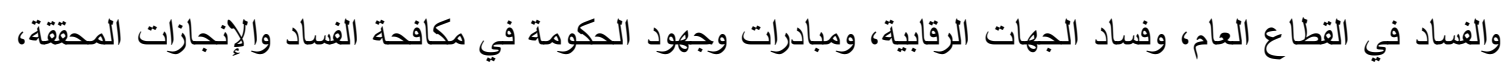

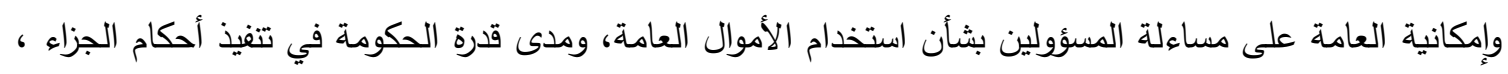

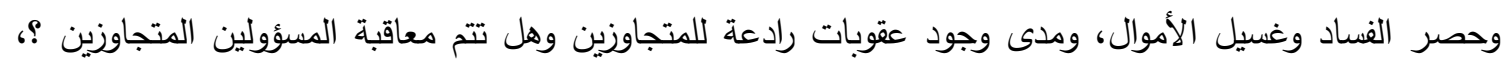

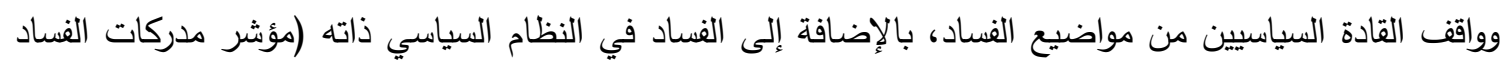

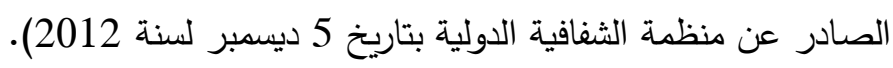

مشكلة (الدراسة:

صادقت دولة الكويت الاتفاقية بموجب القانون رقم 47 بتاريخ 4 ديسمبر 2006 والذي يجعل منها ومن موادها قانونا واجب التطبيق هذا وقد دخلت الاتفاقية حيز النفاذ في علاقة دولة الكويت بالدول الأطراف في تاريخ 16

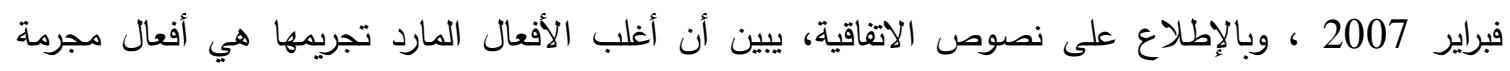

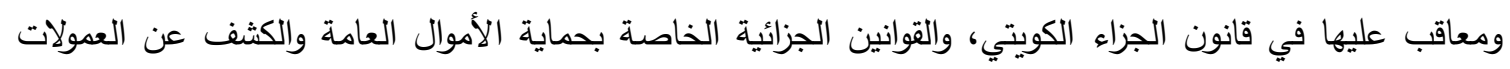

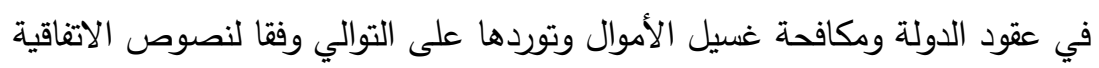

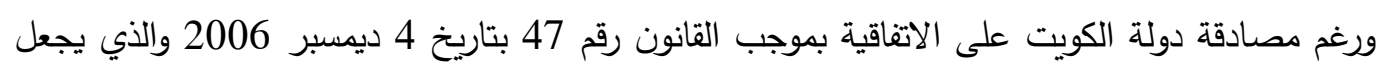
من موادها قانونا واجب التطبيق، وبالإطلاع على نصوص الاتفاقية يتبين أن أغلب الأفعال الواجب تجريمها هي 


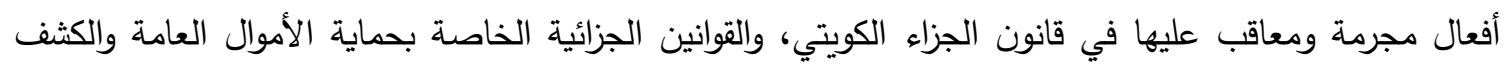
عن العمولات في عقود الدولة ومكافحة غسيل الأموال وتوريدها على التوالي وفقا لنصوص ولئه الاتفاقية : (إدريس،

- رشوة الموظفين العموميين الوطنيين : تجرمها المواد من 35 إلى 43 من القانون العام 31 لسئة 1970 بتعديل بعض أحكام قانون الجزاء رقم 16 لسنة 1960 ـ 196

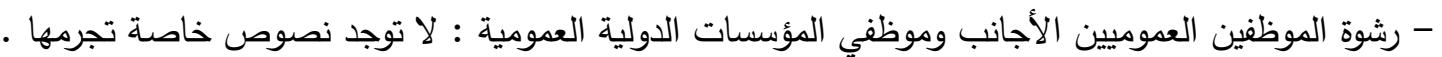
- اختلاس الممتلكات أو تبديدها أو تسريبها بشكل آخر من قبل موظف عمومي : تجرمها نصوص مواد القانون رقم 1 لسنة 1993 بشأن حماية الأموال العامة . - المتاجرة بالنفوذ: يجرمها نص المادة 37 من القانون رقم 31 لسنة 1970 ـ - إساءة استغلال الوظائف : تجرمها المواد 47 - 48 - 49 من القانون رقم 31 لسنة 1970. - الإثراء غير المشروع : لا توجد نصوص خاصة بتجريمه وفقا لنص المادة 20 من الاتفاقية .

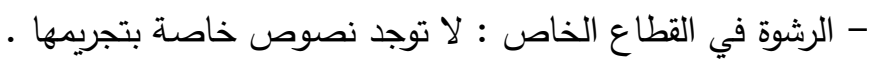

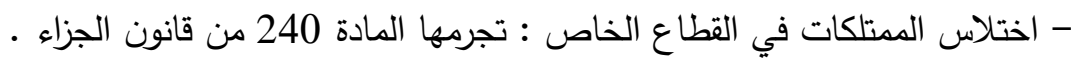
- غسل التحويلات والعائدات الخارجية المشبوهة: يجرمها القانون رقم 35 لسنة 2002 بشأن مكافحة غسيل - الأموال - الإخفاء : تجرمه المادة 49 من قانون الجزاء .

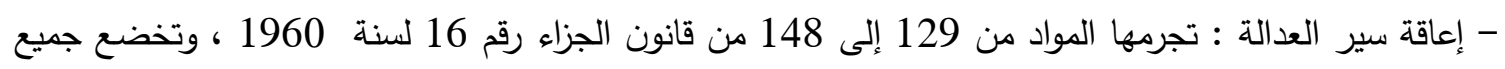
الجرائم بوجه عام لأحكام التقادم المنصوص عليها في قانون الجزاء قانون حماية الأموال العامة طبقا للتعديل الذي نص عليه القانون رقم 31 لسنة 2004 بتعديل بعض أحكام القانون رقم 1 لسنة 1993 بشأن حماية الأموال العامة ـ

مشكلة الدراسة وأسئلتها وضع على الصعيد الدولي مؤشرات تتبت وجود الفساد من عدمه، حيث ظهر لأول مرة هذا المؤشر سنة 1995،

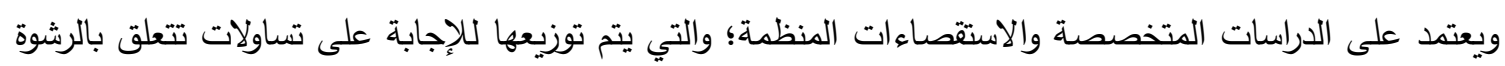
بالقطاع العام، والصفقات العمومية، والمشتريات الحكومية، واختلامس الأموال العامة وكذلك عن كفاءة وفعالية

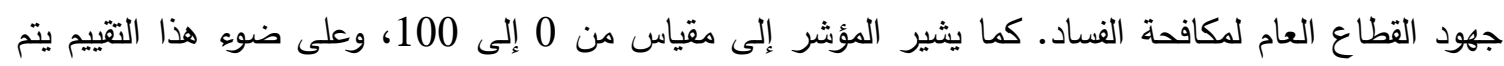
ترتيب الدول في المؤشر تنازليا وفقا لمجموع النقط، حيث تعادل الدرجة 0 أعلى مستوى من مستويات الفساد المدرك، في حين تعادل الدرجة 100 أدنى مستوى من مستويات الفساد المدرك، لذا يلاحظ أن أغلب الدول العربية ترتيبها في النصف السفلي للمؤشره وبتقاط أقل من 40 ٪ وقد أشار تقرير منظمة الثفافية الدولية إلى أن الرشوة

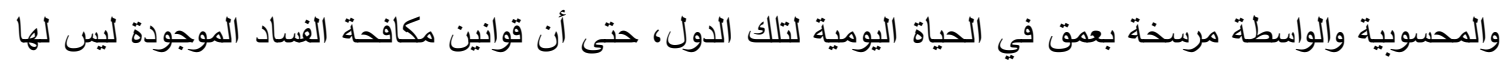
تأثير يذكر • وعليه يمكن تحديد مشكلة الدراسة من خلال الإجابة على السؤال الرئيس الآتي: السؤال الرئيس: ما واقع الفساد المالي في الكويت حسب مؤشر الفساد العالمي ؟ وينبثق عنه الأسئلة الفرعية

1- ما إجراءات دولة الكويت في محاربة الفساد المالي ؟

2- ما أسباب استشراء ظاهرة الفساد المالي بثكل عام ، وفي دولة الكويت على وجه الخصوص؟ 
أهداف الدراسة

هدفت الدراسة الحالية إلى الآتي:

1- التعرف على إجراءات دولة الكويت في محاربة الفساد المالي.

2- التعرف على أسباب استشراء ظاهرة الفساد المالي بثكل عام ، وفي دولة الكويت على وجه الفي الخصوص.

يمكن تلخيص أهمية هذه الدراسة بما يأتي: 1 .نتائج هذه الدراسة تفيد المسؤولين في مكافحة الفساد بدولة الكويت.

2. نتائج الدراسة تفيد المسؤولين في التعرف على أسباب الفساد المالي في دولة الكويت والأخذ بتوصيتها. 4.هذه الدراسة تعد من الدراسات الأولى في دولة الكويت -على حد علم الباحث- والتي تتناول واقع الفساد المالي في الكويت دراسة إجرائية وفق مؤشر الفساد العالمي والقوانين ذات الصلة ، مما قد يُشكل إثراءً لدكتبة علم الإدارة بالجديد من الدراسات.

حدود الدراسة:

تتحدد حدود هذه الدراسة بما يأتي: -الحدود الموضوعية: تتتاول الدراسة واقع الفساد المالي في الكويت دراسة إجرائية وفق مؤشر الفساد العالمي والقوانين ذات الصلة. -الحدود المكانية: تمت هذه الدراسة في دولة الكويت وتحديدا في الجهات الرسمية المسؤولة عن مكافحة الفساد المالي بدولة الكويت المتمثلة في مجلس الوزراء، وهيئة مكافحة الفساد (نزاهة) ووزاتي العدل والداخلية. -الحدود الزمنية: أجريت هذه الدراسة خلال شهر أكتوبر لسنة 2020. -الحدود البشرية: المسؤولين في جهاز مكافحة الفساد بدولة الكويت وعددهم (15) فردا.

مصطلحات الدراسة: قام الباحث بتعريف المصطلحات الواردة في الدراسة وفقاً للتعريفات الواردة في المراجع العربية والأجنبية، وسيتم

تعريف بعض المصطلحات وفقا لخبرات الباحث الذاتية، وفيما يلي تعريف لبعض مصطلحات الدراسة:

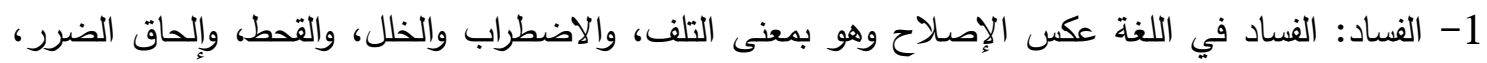
وأخذ المال ظلما (ابن أبو الكرم، 2017) ، ومنه قوله تعالى (ويسعون في الأرض فسادا) (القرطبي، 2015)

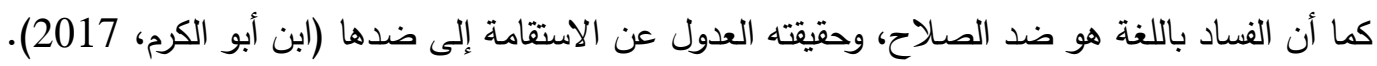
ويعرف الفساد اصطلاحا بأنه اساءة استعمال مركز ما لتحقيق مكسب خاص (محارب، 2016). أما إجرائيا فيعرف الفساد بأنه تقديم المصلحة الثخصية على المصلحة العامة بما يضر بمكان العمل ومصالح الناس الآخرين الذين لا ذنب لهم.

2- الفساد المالي: يعرف الفساد المالي اصطلاحا بأنه ذلك السلوك المنافي للقوانين والاخلاق والقائم على الإخلاد بالمصالح والواجبات العامة من خلال استغلال المال العام لتحقيق مصالح خاصة، وهو ليس حكرا على النشاط الئه

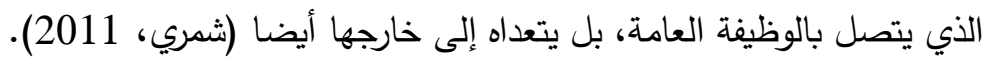


وإجرائيا يمكن تعريف الفساد المالي بأنه العبث بالمال العام لتحقيق مآرب شخصية أو لمصلجة جهة ما، في غياب الرقابة والمحاسبة.

3- مؤشر قياس الفساد الدولي: يغلب عليها قياس مدركات أو تجارب الفساد بإعتبار صعوبة قياس الفساد في حّد

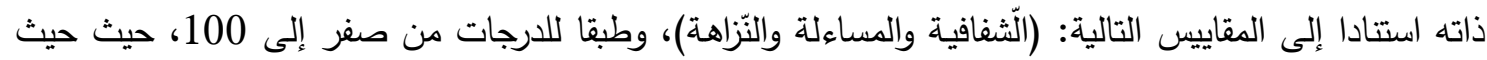

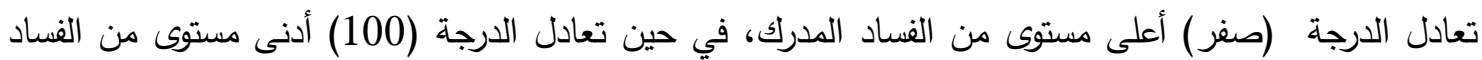

فالثفافية قياس إتاحة المعلومة وفاعليّة الحّق في الوصول إليها وكذلك الوضوح في طرق تسيير القطاع العام. أما المساءلة فهي قياس درجة إستجابة القطاع العام لحاجة أو طلبات المواطنين للحصول على معطيات كافية حول إدارة الّّأن العام ـ في حين تتمثل المحاسبة في قياس فاعليّة مكّونات الحوكمة في منع الفساد (دليل قياس الفساد ومكافحة الفساد ، 2019) إجرائيا فيتقق الباحث مع تعريف البرنامج الإنمائي للأمم المتحدة من ناحية قياس مدركات الفساد طبقا للمؤشرات

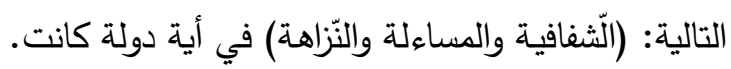

\section{منهج البحث}

اعتمدت الدراسة على المنهج النوعي، وذلك من خلال الاعتماد على تحليل التقارير الرسمية. كما

اعتمدت الدراسة على عدة طرق غير مباشرة لقياس مظاهر الفساد ومدى تفشيه في المجتمعات والمؤسسات، وتعتمد طرق الكثف عن الفساد على مصادر متعددة منها الأجهزة الرقابية بالدولة وتسليط وسائل الإعلام الضوه على عدد من مظاهر الفساد وتفثيه في الأجهزة والمؤسسات المختلفة وكثف مظاهر الفساد من خلال الحملات الإعلامية المركزة ـ هذا إضافة إلى دراسة التقارير الفنية والرقابية للحالات الصادرة من بعض الأجهزة الرقابية في الدولة نحو بعض الجهات والإدارات التي يحتمل انتشار الفساد فيها ، وتقوم منظمة الثفافية الدولية وهي منظمة غير حكومية

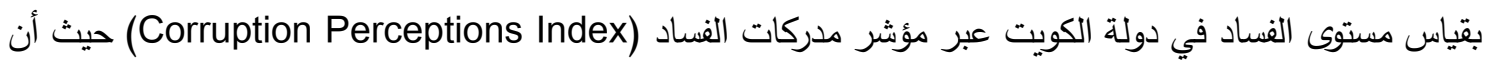
هذا المؤشر هو عبارة عن مصطلح دولي أصدرته المنظمة عام 1955 ، ويقوم على ترتيب الدول حول العالم بناء

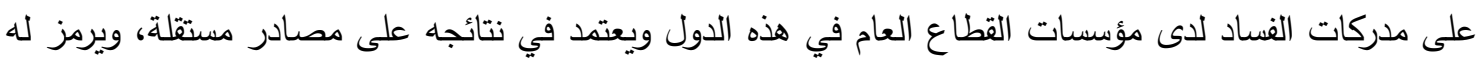
اختصاراً (CPI) ويتدرج المقياس من (صفر) إلى (100) )، حيث تعادل الدرجة (صفر) أعلى مستوى من الفساد المدرك، في حين تعادل الدرجة (100) أدنى مستوى من الفساد المدرك.

\section{مصطلحات ومفاهيم الاراسة}

1- الفساد: الفساد في اللغة عكس الإصلاح وهو بمعنى التلف، والاضطراب والخلل، والقحط، وإلحاق الضرر، وأخذ المال ظلما (ابن أبو الكرم، 2017: 202) ، ومنه قوله تعالى (ويسعون في الأرض فسادا) (القرطبي، 2005:

كما أن الفساد باللغة هو ضد الصلاح، وحقيقته العدول عن الاستقامة إلى ضدها (ابن أبو الكرم، 2017:

ويعرف الفساد اصطلاحا بأنه اساءة استعمال مركز ما لتحقيق مكسب خاص (محارب، 2016: 6).

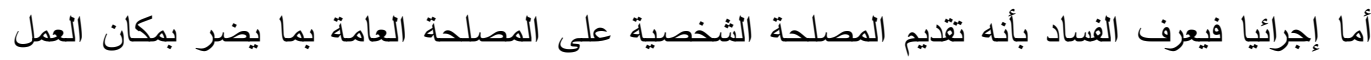
ومصالح الناس الآخرين الذين لا ذنب لهم. 
2- الفساد المالي: يعرف الفساد المالي اصطلاحا بأنه ذلك السلوك المنافي للقوانين والاخلاق والقائم على الإخلال بالمصالح والواجبات العامة من خلال استغلال المال العام لتحقيق مصالح خاصة، وهو ليس حكرا على النشاط

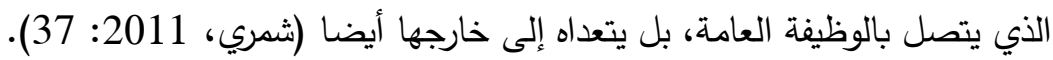

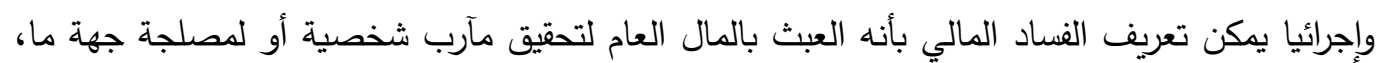
في غياب الرقابة والمحاسبة.

3- مؤشر قياس الفساد الدولي: يغلب عليها قياس مدركات أو تجارب الفساد بإعتبار صعوبة قياس

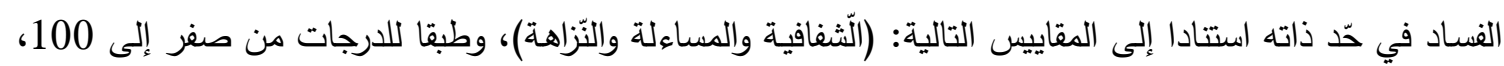
حيث حيث تعادل الدرجة (صفر) أعلى مستوى من الفساد المدرك، في حين تعادل الدرجة (100) أدنى مستوى من

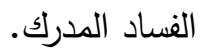
فالثفافية قياس إتاحة المعلومة وفاعليّة الحّق في الوصول إليها وكذلك الوضوح في طرق تسيير القطاع العام. أما

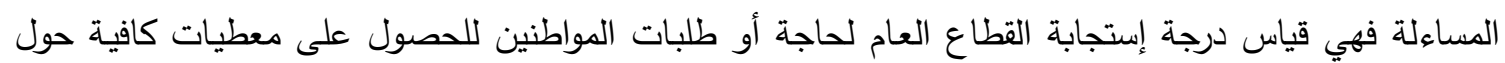
إدارة الثّأن العام ـ في حين تتثثل المحاسبة في قياس فاعليّة مكّونات الحوكمة في منع الفساد (دليل قياس الفساد

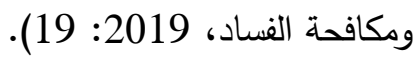
إجرائيا فيتقت الباحث مع تعريف البرنامج الإنمائي للأمم المتحدة من ناحية قياس مدركات الفساد طبقا للمؤشرات التالية: (الثّفافية والمساءلة والنزّاهة) في أية دولة كانت. 4- مؤسسات القضاء على الفساد : وتعرف اصطلاحا بأنها تلك المؤسسات التي تعني بمحاسبة المفسدين والعابثين بالمال العام للدولة، من أجل محاصرة آلة الفساد والقضاء عليه، ويمكن أن تتضمن كل من القضاء والنياء

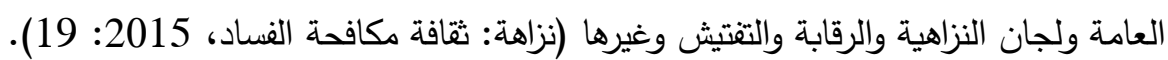

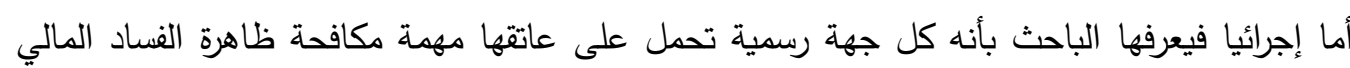
وتجفيف منابعه والحد منه ومحاسبة مرتكبيه أيا كانت درجتهم ومركزهم الوظيفي في الدولة. 5- قوانين محاربة الفساد: هو القانون التشريعي الذي يهدف إلى مكافحة الفساد في كافة المؤسسات، والثركات، وديات وجهات العمل التي تتبع للدولة، أو توجد على أراضيها، ويهدف قانون مكافحة الفساد، إلى حل كافة قضايا الفساد،

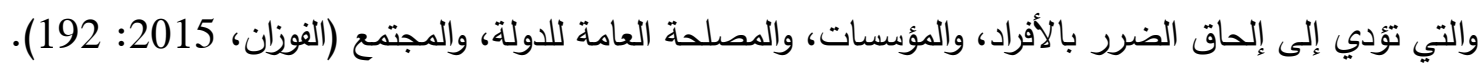

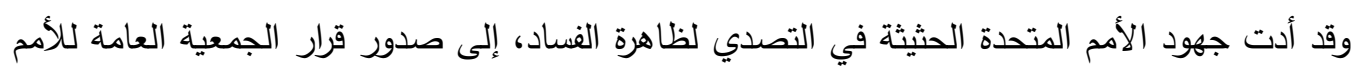
المتحدة رقم (61/55) في 4 ديسمبر سنة 2000 وعليه تم إنثاء لجنة متخصصة للتفاوض بثأن صك قانوني دولي فعال لمكافحة الفساد، وبتاريخ 31 أكتوبر سنة 2000 صدر قرار الجمعية العامة للأمم المتحدة رقم (4/58) باعتماد اتفاقية الأمم المتحدة لمكافحة الفساد، كما طالب وحث القرار المجتمع الدولي ومنظمات التكامل الاقتصادية الإقليمية على اعتماد الاتفاقية الدولية لككافحة الفساد، التي عرضت للتوقيع في 11 ديمسبر 2003 ، في مدينة ميريدا المكسيك، ودخلت حيز النفاذ بتاريخ 14 ديسمبر 2005 لتصبح بذلك أول اتفاقية دولية عامة معنية ومختصة بحصر مجموع التدابير وحصر الإجراءات الواجب على المجتمع الدولي والدول اتخاذها والإلتزام بها، لضمان مكافحة الفساد والقضاء عليه (دليل قياس الفساد ومكافحة الفساد، 2015).

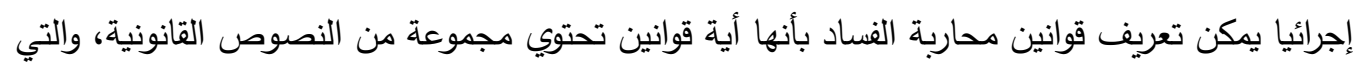

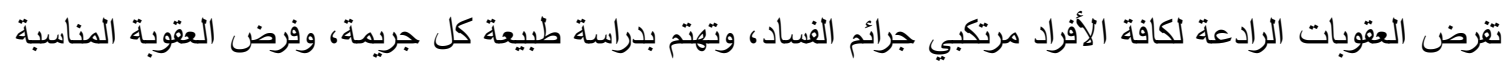

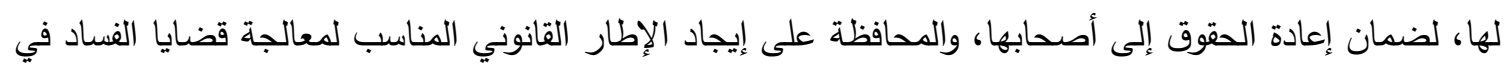
المجالات السياسية، والاقتصادية، وغيرها. 
الإطار النظري والدراسات السابقة مؤشرات ودلائل الفساد المالي

يعد الفساد والرشوة من أهم أربعة عوامل تعوق الاستثمار والتتمية في منطقة الثرق الأوسط وشمال

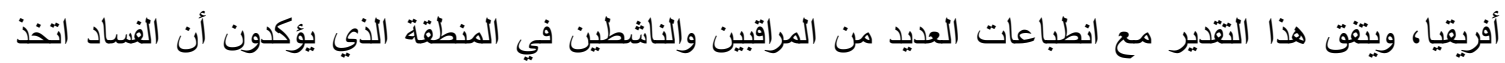

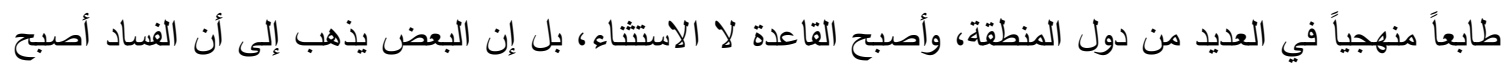
أداة من أدوات الحكم والإدارة في العديد من دول المنطقة، كما تؤكد إحصاءات البنك الدولي ومنظمة الثفافية

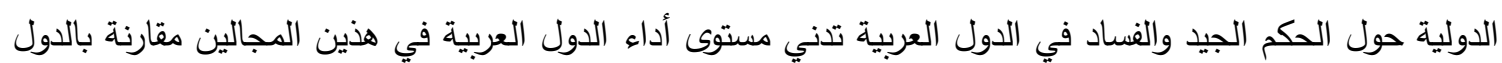
الأخرى، فأداء دول الثرق الأوسط وشمال أفريقيا في مجال المسائلة الداخلية، طبقاً للبنك الدولي، مشابه لأداء دول

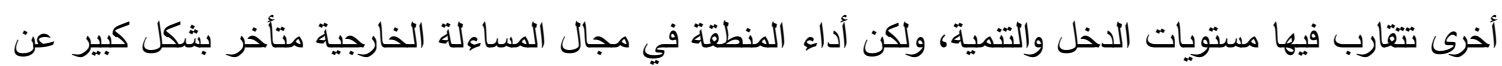

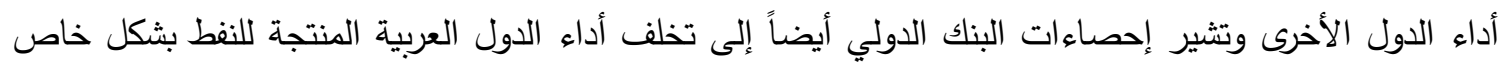
في مجال المساءلة الخارجية (عبد المجيد، 2018). يرجع ضعف أداء الدول العربية على مؤشر مدركات الفساد طبقاً لهيئة الثفافية إلى عدة أسباب، أهمها

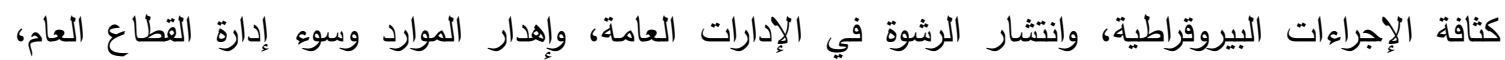
والاختلاسات وغسيل الأموال والتقاعس في ملاحقة جرائم الفساد. كما تعرقل القيود التي تضعها الحكومات في في

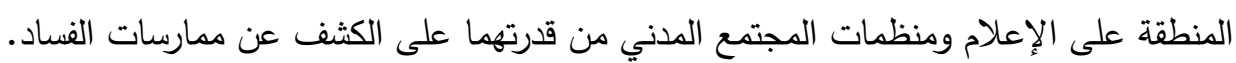

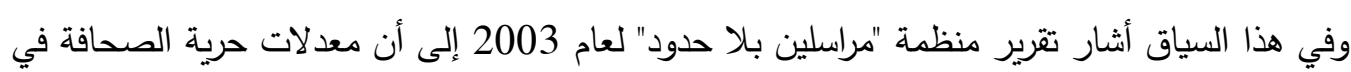
الدول العربية هي الأسوأ في العالم، ويشدد العديد من المراقبين على ضرورة اعتماد قوانين تحمي حرية واستقلال الإعلام ومنظمات المجتمع المدني في المنطقة مما يعزز من قدرتها على ممارسة الرقابة الثعبية على الحكم (الثريف، 2016).

كما تثير هيئة الثفافية إلى الدور السلبي الذي تلعبه الثركات الغربية واستخدامها للرشوة في معاملاتها

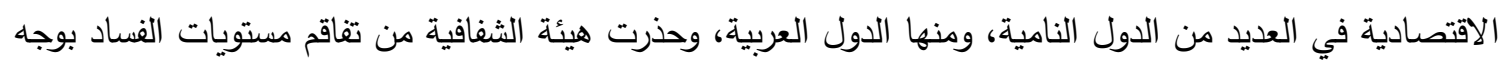
خاص في قطاع البترول في عدد من الدول التي حصلت على درجات منخفضة للغاية على مؤشر مدركات الفساد، ومنها عدد من الدول العربية، وهي العراق وليبيا والسودان واليمن. وحثت هيئة الثفافية الدول الغربية على إلزام شركات البترول التابعة لها على الإفصاح عن المدفوعات التي تقدمها لحكومات الدول المنتجة للبترول، وعلى ولى ولى ولى ولئه

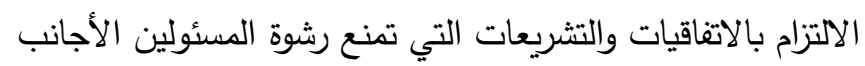

إلا أن الباحث يرى بأن الدرجات المرتفعة نسبياً التي حصلت عليها دول الخليج على مؤشر مدركات الفساد مقارنة بالدول العربية الأخرى لا تعبر بالضرورة عن تدني مستويات الفساد في تلك الدول خاصة أنها طبقاً لتقرير البنك الدولي تفتقر إلى آليات المساءلة الخارجية بالإضافة إلى ضعف لإلى آليات المساءلة الداخلية فيها، وفي الدول العربية بشكل عام.

إن تفوق دول الخليج على مؤشر مدركات الفساد قد يرجع إلى فاعلية تلك الدول في التستر على

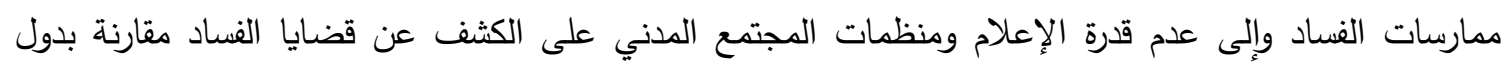

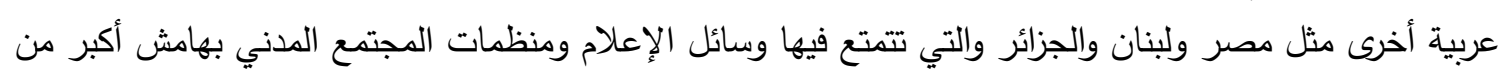

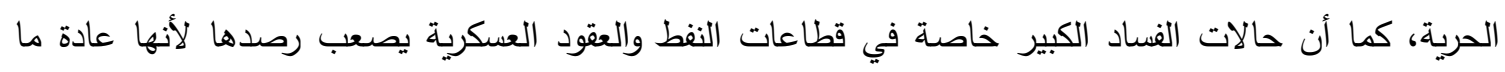
تكون محاطة بالسرية، ويتم التفاوض عليها بين الدول والثركات الكبرى، وللتعرف على واقع الفساد والرشوة في 
العالم العربي بشكل أفضل نستعرض في الجزء التالي بعض قضايا الفساد التي شغلت الرأي العام على مدى الأعوام الماضية في عدد من الدول العربية وبعض الإجراءات التي اتخذت لمكافحة الفساد. وأشار التقرير إلى تفشي الفساد

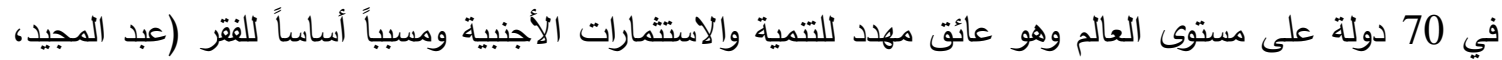
.(2018

وتجدر الإثارة إلى أن المنظمة تعتمد على 16 استطلاع رأي ومسح تقوم بها 10 مؤسسات مستقلة

معروفة بمصداقيتها دولياً منها جامعة كولومبيا ومنها الـ (Freedom House) ، وهذه الاستطلاعات تكون نتيجة دراسة موثوقة تؤدي إلى النتيجة التي تعلن سنوياً بقائمة مدركات الفساد. وتعتمد هذه الدراسات بشكل عام على وهلى

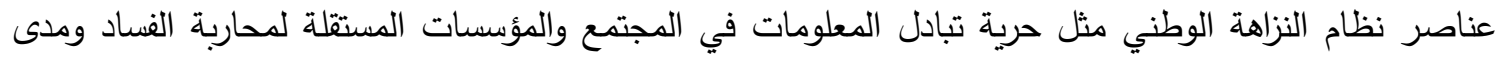

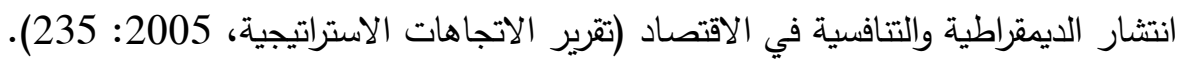
ويمكن القول بصفة عامة أن ممارسات الفساد تتركز في المجالات التالية: (تقرير الاتجاهات

الاستراتيجية، 2005: 241)

1- العقود الحكومية: حيث يمكن أن يؤدي الفساد إلى تخصيص العقود الحكومية إلى جهات فتقد الكفاءة، كما يؤدي الفساد إلى عدم الالتزام والتلاعب بشروط العقود الحكومية. 2- توزيع الخدمات والمرافق والأراضي التي تمنحها الحكومة، فقد يمكن أن يؤدي الفساد إلى توزيع تلك المنافع

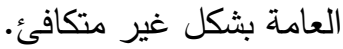
3- الإيرادات الحكومية: مثل الضرائب والجمارك والتي يمكن تخفيضها من خلال رشوة الموظف المختص عن تحصيلها. 4- الإجراءات البيروقراطية وإجراءات استخراج التراخيص حيث يمكن أن يؤدي الفساد إلى تجنب وتسريع تلك

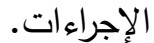

5- الإجراءات القانونية التي يمكن أن يؤدي الفساد فيها إلى تعطيل تللك الإجراءات من خلال رشوة القائمين على أجهزة الأمن والشرطة ومن خلال الجهاز القضائي نفسه. 6- التوظيف وتوزيع المناصب العامة حيث يمكن أن تؤدي الرشوة والمحسوبية إلى توظيف الأقارب والأصدقاء دونا

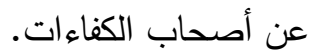

وهناك من قسّم الحكومات الفاسدة بحسب أشكال الفساد وصوره التي تعرفهاء ونكون هنا أمام نوعين من الحكومات: حكومات ينتشر فيها الفساد في المستويات العلياء وحكومات ينتشر فيها الفساد في المستويات الدنيا. فالأولى تكون الحكومة ما حكومة لصوص وإمًا حكومة احتكار ثنائي (النخبة الحاكمة والأوليغارشية المستفيدة)، وفي في فئرئ

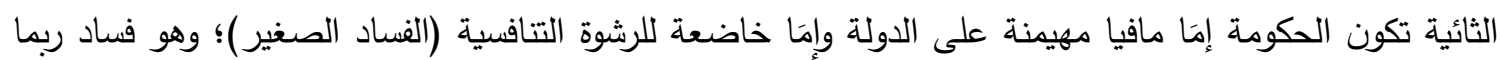
يتطور إلى أكثر من ذلك. 
جدول (1)

أنواع الحكومات الفاسدة

\begin{tabular}{|c|c|c|}
\hline المرتون| & المرتشون متعددون & \\
\hline المكانية التطور & & \\
\hline
\end{tabular}

(Ackerman, 2011, p.344)

مسببات الفساد المالي

كما تتعدد أشكال الفساد ودرجاته فإن أسبابه أيضاً متعددة ومركبة، وتوجد عدة وجهات نظر حول أهم

أسباب الفساد، فهناك من يرون أن ظاهرة الفساد مرتبطة في الأساس بدرجة تطور المجتمع الاقتصادية والاجتماعية

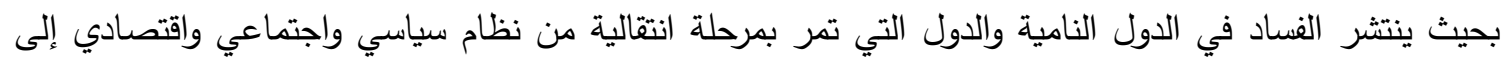
نظام آخر • وطبقاً لهذا الرأي فإن ضعف موارد الدولة وانخفاض الرواتب والأجور في الدول النامية يؤدي إلى تفشي

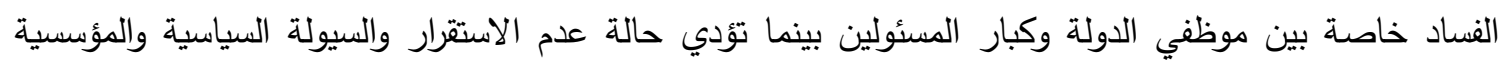
وطرح أصول ضخمة للبيع السبب الرئيسي وراء تفشي الفساد في الدول التي تمر بمرحلة انتقالية (الرفاعي،

نظرية قياس مؤشر الفساد

تقوم نظرية قياس مؤشر الفساد أساس على وجود مؤشر مركب عادة ما يصدره البنك الدولي، ويشمل

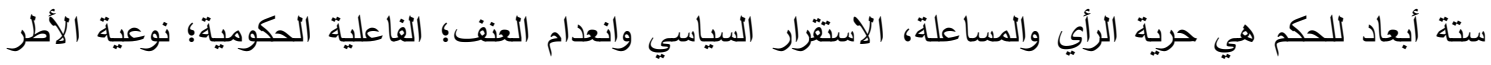
التتظيمية؛ سيادة القانون؛ السيطرة على الفساد. بدأ هذا المؤشر في عام 1996 حيث أخذ يستتبط بياناته من 37 قاعدة معلومات أنشنت بواسطة 31 مؤسسة متخصصة. يقيس هذا المؤشر الحالة في دولة ما ويقارنها بذاتها خلال الأعوام التي يملك إحصاءاتها أي منذ عام 1996؛ في ما يخص معظم الدول؛ ويقوم بتصحيح حتى الأرقام التي يكون قد أعطاها سابقا في حال توصّله إلى معلومات جديدة تخص بلدا ما، وهاء وهو راح في السنوات الأخيرة يصدر

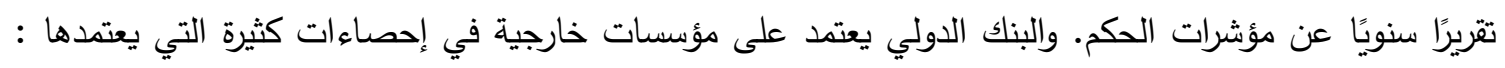

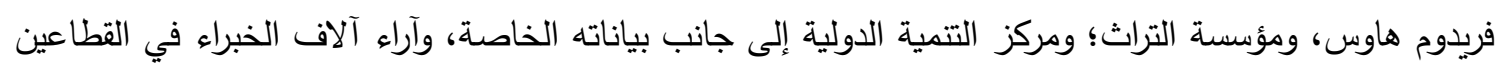
الخاص والعام والمنظمات غير الحكومية؛ ومنظمات المجتمع الدني. وهذا ما يجعل مؤشر البنك الدولي, مثل باقي

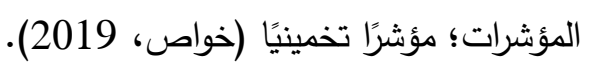

مع التسليم بصعوبة قياس الفساد؛ فإن من الممكن إجراؤه بطرانق عدة؛ ومن خلال عدد من الأساليب

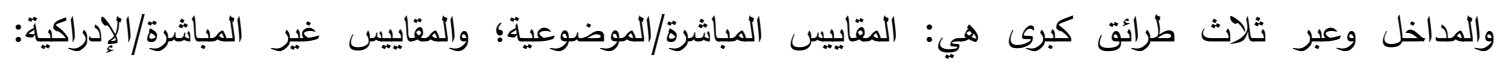
والمقاييس الوسيطة/الاستعداد المؤسسي. كما يمكن إجراء القياس عبر العوامل والاسباب المؤدية إليهه أو عبر التبر

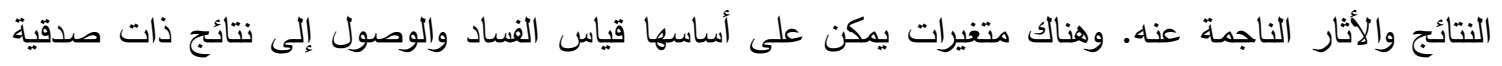
(أنظر شكل-1) من خلال طريقتينعلى وجه الإجمال: إحداهما هي طريقة القياس المباشر الذي يعتمد على ما لئى تملكه الأجهزة الرسمية المعنية بمحاربة الفساد، والأخرى هي طريقة القياس غير المباشر الذي يستئد إلى اتطباعات 
الجمهورء وكلاهما يرتكز على ثلاثة متغيرات: العوامل والمقومات المانعة للقساد؛ وجود ممارسات الفساد؛ وجود

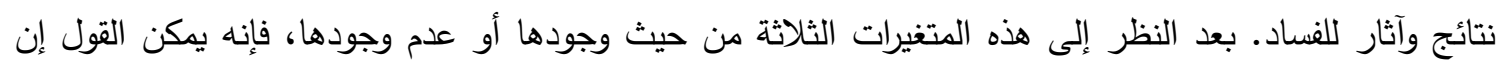
هناك فسادا أو لا يوجد فساد. في هذه الدولة أو تلك.

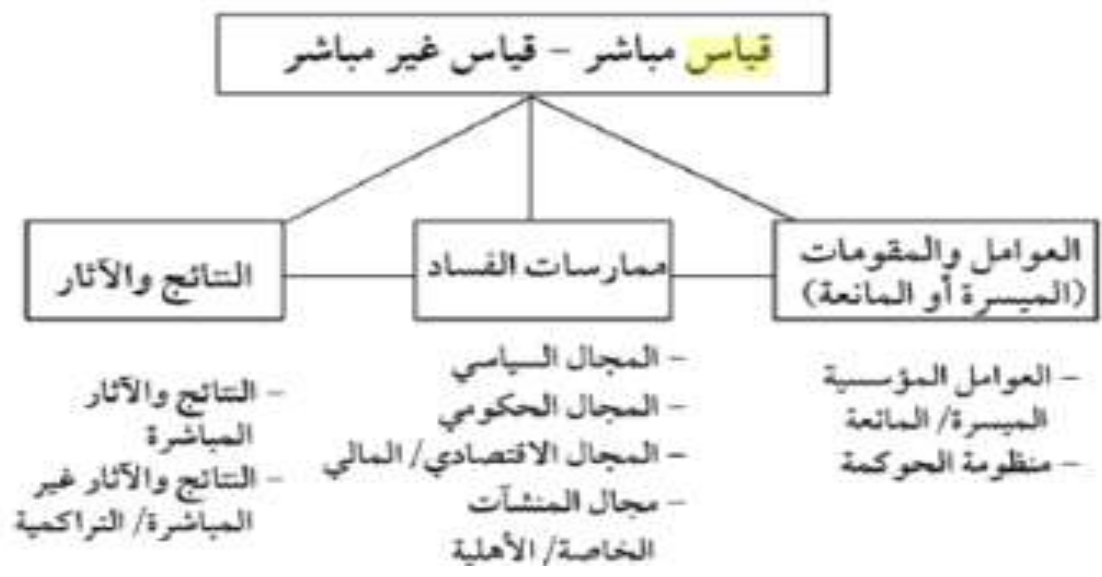

شكل (1)

متغيرات يمكن على أساسها قياس الفساد

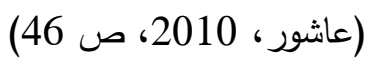

تعُُ المقاييس المباشرة صادقة إلى حد ماء وخالية من التخمين والتوقع؛ فهي تجمع عدد الحالات التي

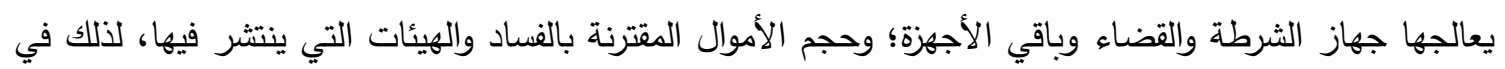
النهاية يمكن أن تتوافر مؤشرات حقيقية عن حجم الظاهرة في البلد والقطاعات التي تتنشر فيها أكثر مقارنة

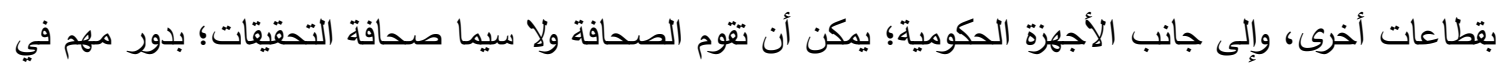
الكثف عن حجم الفسادء وتسليط الضوء على المؤسسات التي ينتثر فيها الفساد بقوة. هذه الأطراف الحكومية

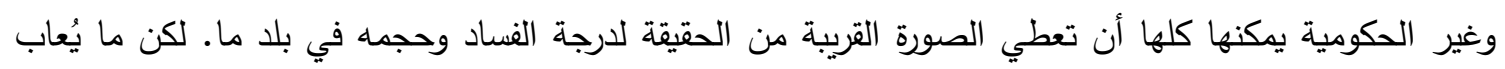
على المقاييس المباشرة/الموضوعية أنها مرتبطة في كثير من الأحيان، إن لم يكن دائماء بمدئ فاعلية الشرطة

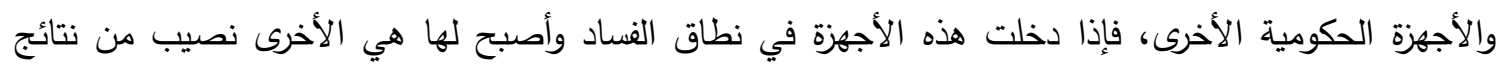
الفساد المالية، يكون من الصعب كثف درجة الفساد في البلاد وحجم انتشاره. وحتى لو عملت الأجهزة المشار إليها

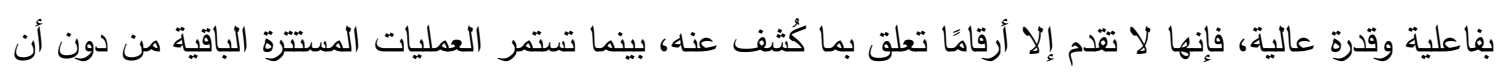

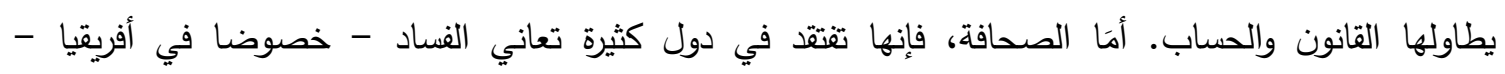

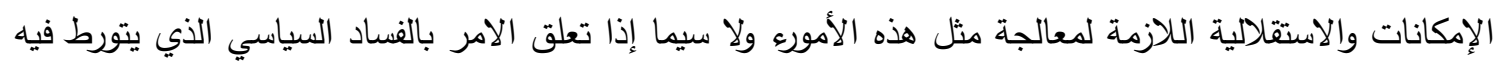

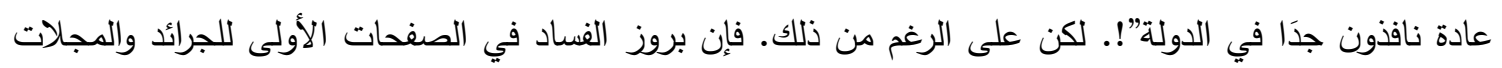

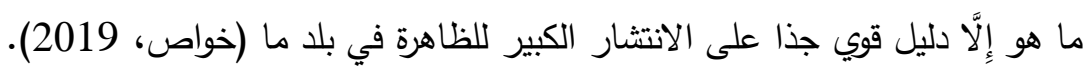

الارراسات السابقة

تم تقسيم الدراسات السابقة التي تتاولت متغيرات البحث وذلك تصاعديا من الأحدث إلى الأقدم - خلال

السنوات العشرة الأخيرة - سواء العربية منها أو الأجنبية كما يلي: 1- دراسات تتاولت الفساد المالي من حيث أنواعه ومظاهره وأسبابه وطرق الحد منه وما إلى ذلك. لإنية 
استهدفت دراسة بلبال (2019) التطرق إلى موضوع الفساد بصفة عامة والفساد الإداري والمالي بصفة خاصة، من خلال التركيز على تبيان أهم الأسباب المؤدية إلى بروز هذه الظاهرة وانتشارها بصفة سريعة في مختلف المجتمعات المتقلمة والنامية بدرجة أعلى، حيث إن تسليط الضوه على منى مسببات هذه الظاهرة من خلال تمحيصها وتحديد مجالاتها يساهم بشكل كبير في بناء استراتيجيات لـكافحتها بغية تحقيق محتمعات خالية من هذه الممارسات والسلوكات السلبية. وقد توصلت الدراسة بان هذه الظاهرة عبارة عن سلوكات وممارسات منحرفة وغير

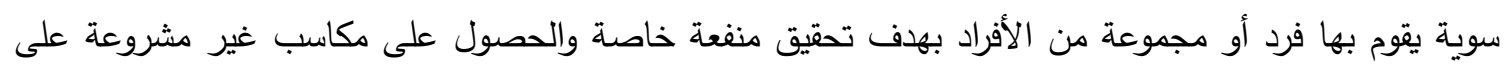

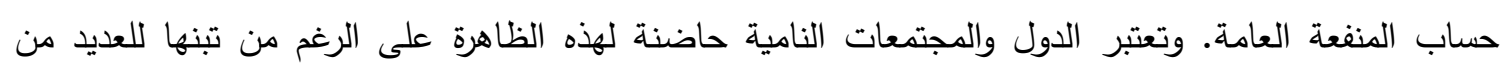

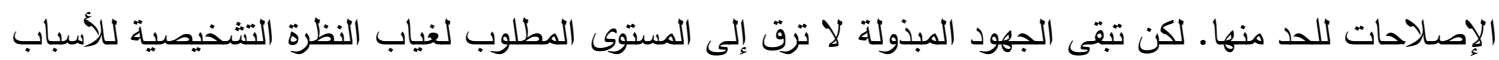

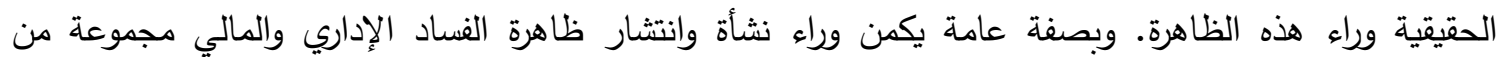
الأسباب المرتبطة بخصائص ومميزات البيئة السياسية الاقتصادية والاجتماعية والثقافية من جهة، وبالنظم الإدارية والقانونية المطبقة من جهة ثانية. إلا أنه يبقى غياب الرقابة الذاتية، ونقص الوازع الديني والأخلاقي من أهم

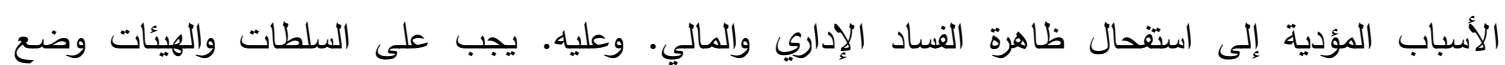

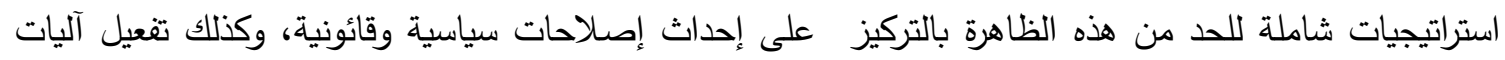
الرقابة والثفافية من خلال معاقبة المتورطين في قضايا الفساد. مهما كانت صفتهم ومستوى نفوذهم. بالإضافة إلى إلى العمل على نشر الوعي عبر مختلف الوسائل بهدف تتشئة جيل يمقت هذه الظاهرة ويحاربها. ولعل الإصلاح

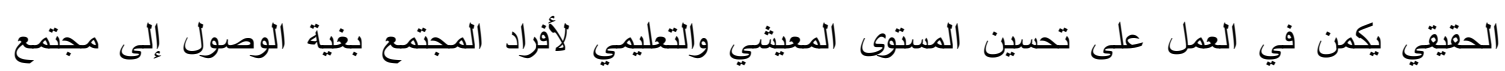
أخلاقي.

كما تتاولت دراسة معتوق (2019) تقديم إطار تحليلي متكامل لمفاهيم الفساد، وكذا التعرف على الفساد

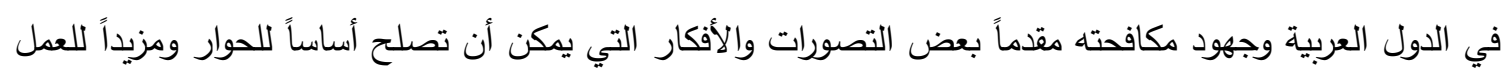
في هذا المجال. وقد تم اعتماد المنهج الوصفي التحليلي، وذلك بالاستتاد إلى واقع المعلومات والنشرات والدراسات

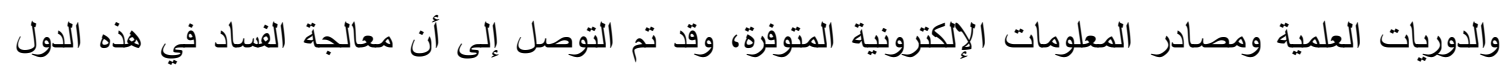

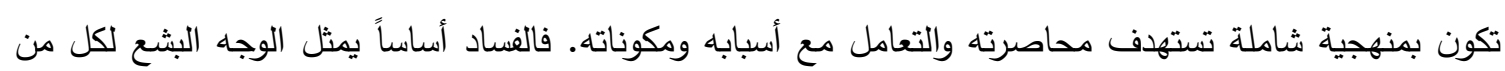
السلطة والإدارة.

هدفت دراسة حنا (2016) إلى الإجابة على التساؤل الآتي: هل أسهح بالفعل مؤشر مدركات الفساد الخاص بمنظمة الثفافية الدولية في تدعيم آليات مكافحة الفساد. أم هو فقط علامة تجارية ترويجية لدور منظمة الآنة الثفافية. وبعبارة أخرى هل يقدم مؤشر مدركات الفساد جوابا منطقيا للتساؤل المستوحى من كتابات مارك بوكانان ام

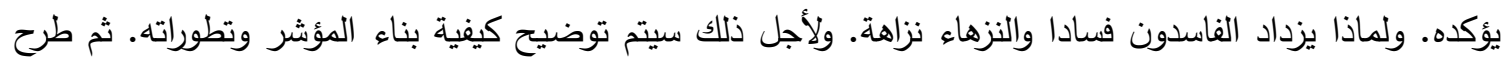

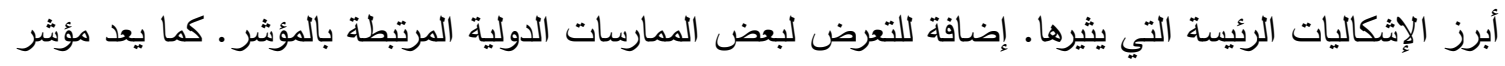

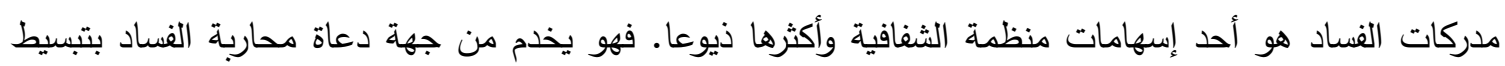

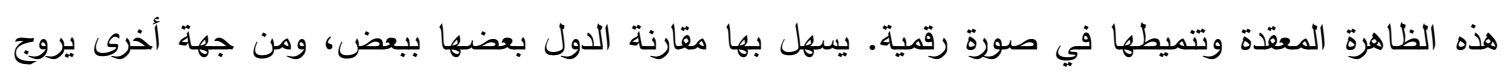

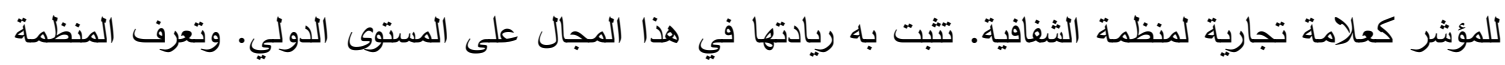

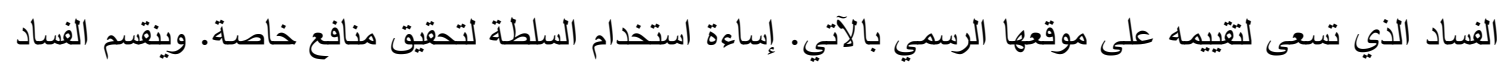
هنا إلى مستويين. الأول يتعلق بالفساد الكبير الذي يمارسه الموظفون في المستويات العليا في جهاز الدولة أو في السلطة المركزية. اما المستوي الثاني فهو الفساد الصغير الذي يمارسه موظفو الدولة في الفئلئ المستويات الوسطي

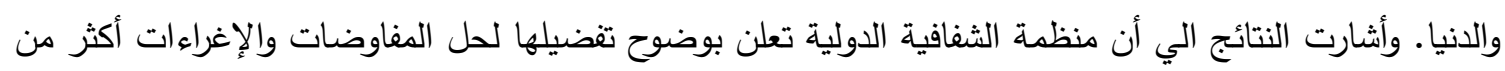


سياسة الإنذارات والإيماءات السلبية في مجال مكافحة الفساد. فبحسب مؤشرها لمكافحة الفساد. فإن الدول المتأخرة في التصنيف تعاني من فساد الذمم بجانب الفساد المالي هدفت دراسة يونس (2016) إلى الكثف عن آليات مكافحة الفساد المالي، واعتمدت الباحثة على المنهج الوصفي، حيث تتاولت الدراسة عدة محاور، أوضح المحور الأول تعريف الفساد، فالفساد مصطلح يتضمن معاني عديدة في طياته وهو موجود في كل القطاعات الحكومية منها والخاصة وفي أي تنظيم يكون للشخص فيه قوة الشعرل

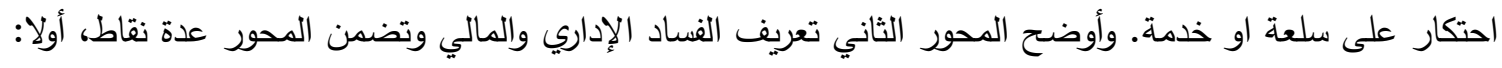
الفساد السياسي، وهو يتمثل في الانحراف عن المنهج المحدد للمنظومة السياسية والحزب. ثانيا: الفساد الإداري، ويتمثل في الانحراف الإداري أو الوظيفي والذي يصدر من الموظف العام. ثالثا: الفساد المالي، وامثلته الانحراف

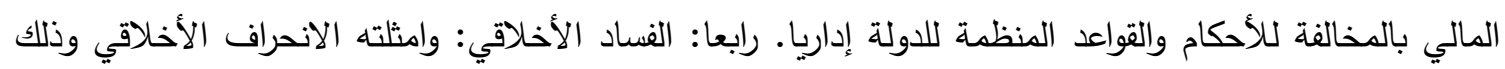

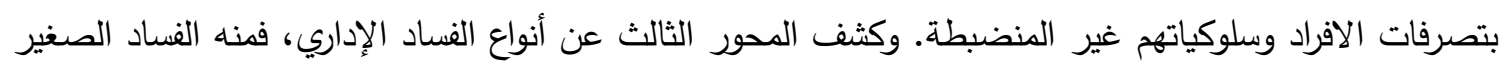

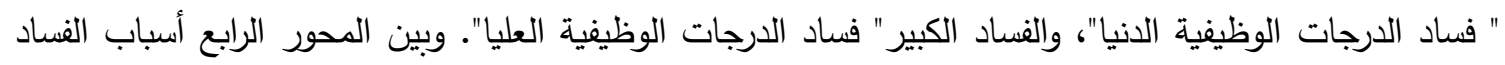
وتتاول المحور عدة نقاط (أسباب سياسية، أسباب اجتماعية، أسباب اقتصادية، أسباب إدارية تتظيمية). واختتم

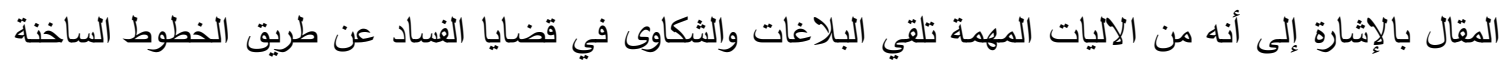
وصناديق الثكاوى داخل المؤسسات أو الصناديق البريدية الواضحة بشرط التأكد من قبل الجهات الرسمية من التهات الثخص المبلغ وعنوانه مع العقوبة الرادعة في حالات البلاغات الكاذبة والكيدية.

كما هدفت دراسة سهيلة (2015) إلى التعرف على مظاهر وأسباب الفساد المالي في العراق، حيث التهابه اعتمدت الباحثة على المنهج الوصفي ، وقد توصلت بأن ظاهره الفساد المالي تعتبر من الظواهر الخطيرة التي تواجه البلدان وعلى الأخص الدول النامية حيث أخذت تتخر في جسم مجتمعاتها بدأت بالأمن وما تبعه من شلل في في تئي عملية البناء والتتمية الاقتصادية والتي تنطوي على تدمير الاقتصاد والقدرة المالية والإدارية وبالتالي عجز الدولة

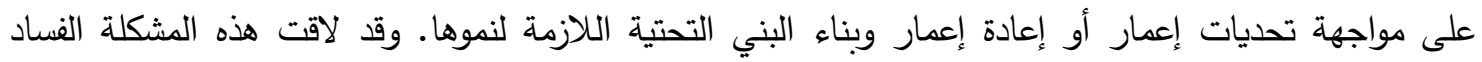

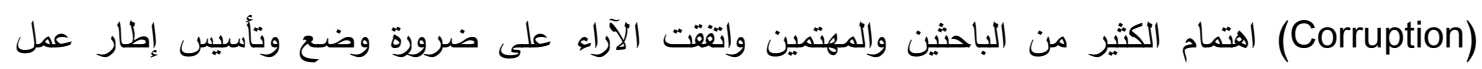
مؤسسي الغرض منه تطويق المشكلة وعلاجها من خلال خطوات جديه ومحدده ومكافحة الفساد بكل صوره ومظاهره

وفي كافة مجالات الحياة لتعجيل عملية التتمية الاقتصادية. تتاولت دراسة بوفاسة (2014) ظاهرة الفساد المالي والإداري من خلال التعريف به وأسباب حدوثه والآثار الناجمة عنه، ثم الوسائل المكنة لمكافحته، أي: ما هي السبل والإجراءات الكفيلة للحد من أثار الفساد المالي والإداري؟ واستعملنا المنهج الوصفي التحليلي، وافترضنا أن هناك عدة وسائل للحد من الظاهرة، لنادئ لنخرج بنتيجة مفادها أن الفساد قد استفحل في الجزائر ولابد من إرادة قوية لدى المجتمع لتدعيم تلك الوسائل.

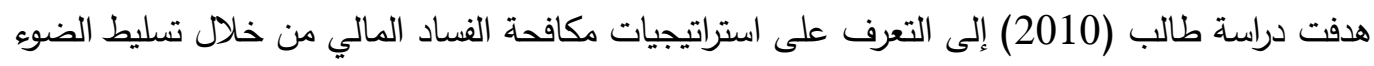
على أهم الإستراتيجيات التي اتبعتها الدول العربية من منظور عدد من الكتاب والباحثين العرب فضلاً عن ممارسات بعض المؤسسات العربية التي تسعى لمكافحة هذه الظاهرة. وقد توصلت الدراسة بأن تعدد أسباب الفيات الفياد الإداري

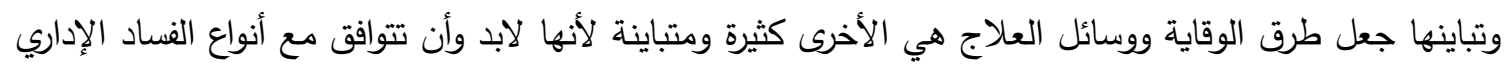

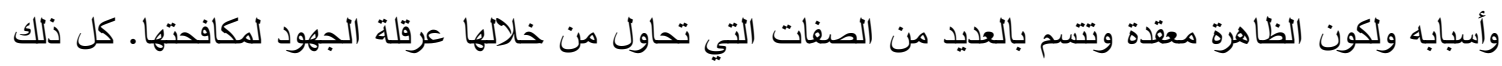
تطلب من المعنيين وضع الاستراتيجيات للوقاية من الفساد الإداري أو إستراتيجيات العلاج والمكافحة مع الونسي الوعي الكامل بالسمات الأساسية لهذه الظاهرة. 
هدفت دراسة عبود (2010) إلى تحليل صور وأسباب الفساد المالي والإداري في محافظة الديوانية بالعراق، وقد

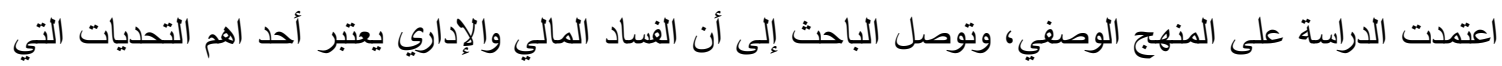

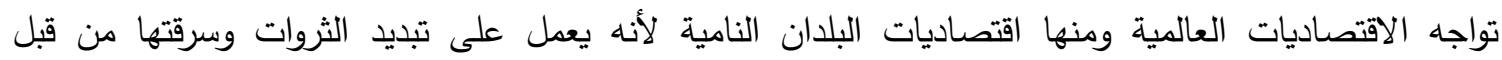
المفسدين أو استثمارها في مجالات غير منتجة وغير مفيدة .وانطلاقا من تلك الخطورة سعت العديد من الدول

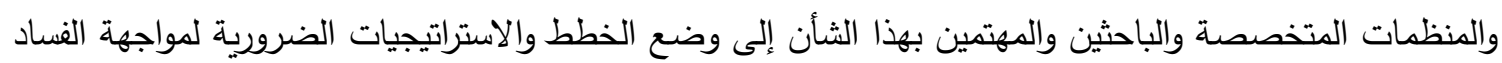

$$
\text { والإطد من أثاره. }
$$

يتتاول هذا الجزء إجراءات دولة الكويت في محاربة الفساد المالي، وعرض للتقارير المحلية والدولية ومناقشتها التي تتعلق بمستويات الفساد المالي بدولة الكويت، وما نتج عنه من آثار على النمو الاقتصادي في البلاد وعرداد وذلك خلال الفترة الممتدة من 2015 إلى 2020.

إجراءات دولة الكويت في محاربة الفساد المالي صادقت دولة الكويت الاتفاقية بموجب القانون رقم 47 بتاريخ 4 ديسبر 2006 والذي يجعل منها ومن موادها قانونا واجب التطبيق هذا وقد دخلت الاتفاقية حيز النفاذ في علاقة دولة الكويت بالدول الأطراف في تاريخ

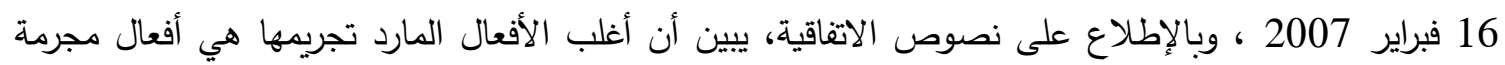

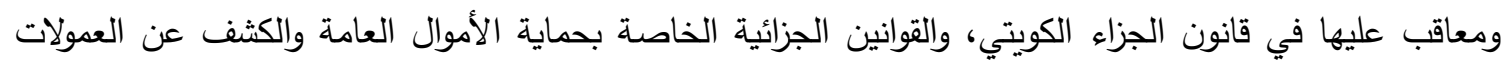
في عقود الدولة ومكافحة غسيل الأموال وتوردها على التوالي وفقا لنصوص الاتفاقية : (الكويت، وزارة العدل، $(2008$

- رشوة الموظفين العموميين الوطنيين : تجرمها المواد من 35 إلى 43 من القانون العام 31 لسنة 1970 بتعديل بعض أحكام قانون الجزاء رقم 16 لسنة 1960 ـ 1960

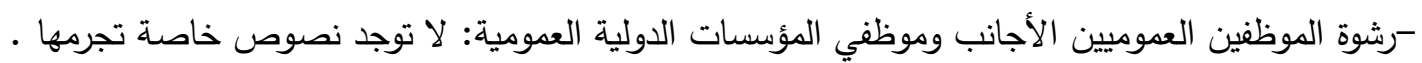

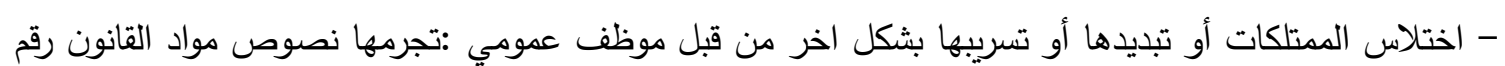

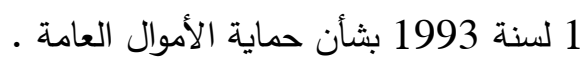

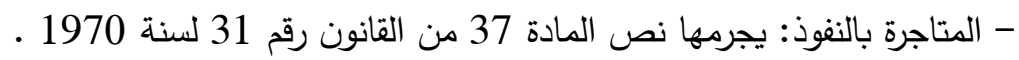

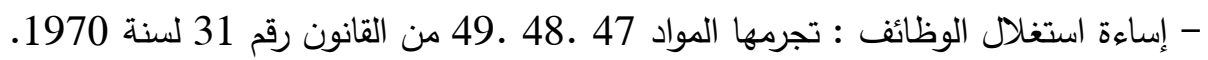
- الإثراء غير المشروع : لا توجد نصوص خاصة بتجريمه وفقا لنص المادة 20 من الاتفاقية .

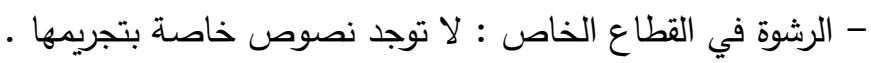

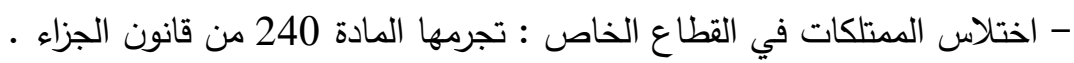
- غسل العائدات الإجرامية : يجرمها القانون رقم 35 لسنة 2002 بشأن مكافحة غسيل الأموال.

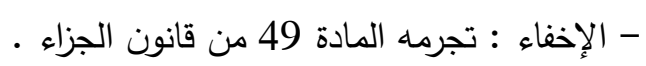
- إعاقة سير العدالة : تجرمها المواد من 129 إلى 148 من قانون الجناء الجزاء رقم 16 لسنة 1960. وتخضع جميع الجرائم بوجه عام لأحكام التقادم المنصوص عليها في قانون الجزاء رقم 16 لسنة 1960

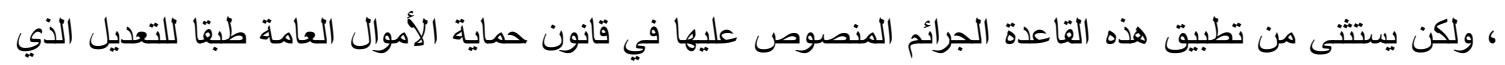
نص عليه القانون رقم 31 لسنة 2004 بتعديل بعض أحكام القانون رقم 1 لسنة 1993 بثأن حماية الأموال العامة • ويوجد ضمن التشريع الوطني آليات للتعاون بين السلطات الوطنية والقطاع الخاص من أجل مكافحة الفساد حيث 
ينظم هذا التعاون القاتون رقم 32 لسنة 1968 بشأن بنك الكويت المركزي والمهنة المصرفية والقوانين المعدلة له على آلية التعاون بين البنك المركزي وبنوك القطاع الخاص في هذا الثأن ـ وبشأن تدابير النزاهة بين أعضاء

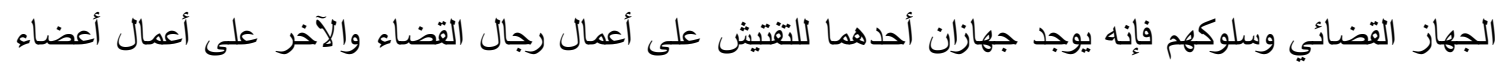
النيابة العامة وهما تابعان للمجلس الأعلى للقضاء طبقا للقانون رقم 22 لسنة 1990 في شأن تتظيم القضاء (الصالح، 2014).

كذلك فإن ثمة اقتراحات بقوانين معروضة - حاليا - على البرلمان للكثف عن الذمة المالية وحق

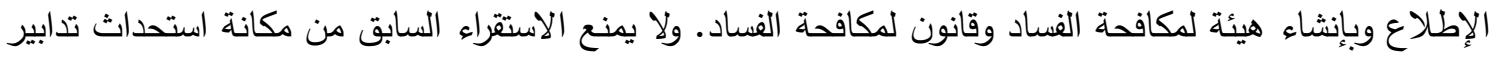
تشريعية أخرى لتغطية الحالات التي نستلزم تدخل المشرع ومواجهة ما يستجد من جرائم ـ كما تتوافر في الدولة أجهزة رقابية للوقاية من الفساد ومكافحته وأهمها ما يلي : (الكويت، وزارة العدل، 2008). 1- ديوان المحاسبة بموجب القانون رقم 30 لسنة 1964 ـ 2- البنك المركزي وفقا لما ورد النص عليه في القانون رقم 35 لسنة 2005 بشأن مكافحة غسيل الأموال . 3- سلطات الجمارك المختصة وفقا لنصوص قانون مكافحة غسيل الأموال سالف الذكر أيضا . 4- أجهزة الثرطة والبحث الجنائي التي تتظم عملها كافة القوانين الخاصة بهيئة الشرطة. 5- ووفقا للمادة 8 من القانون رقم 1 لسنة 1993 بثأن حماية الأموال العامة شكلت بمجلس الأمة لجنة حماية

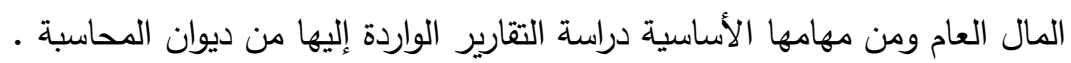

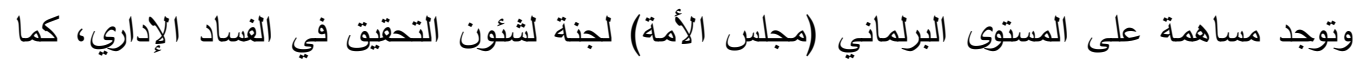
توجد على المستوى الثعبي في إطار عمل جمعيات النفع العام التي تخضع لإشراف وزارة الثئون الاجتماعية والعمل والتي منها على سبيل المثال جمعية الثفافية الكويتية والجمعية الاقتصادية ـ كما أصدر مجلس الوزراء قراره رقم 942/ ثانياً نص من الموافقة على مشروعات القرارات التالية: (إدريس، 2015).

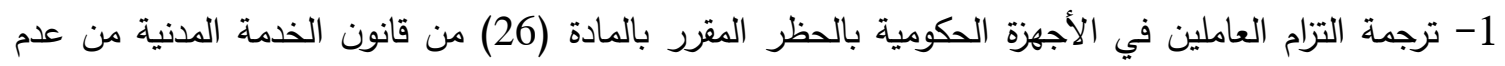

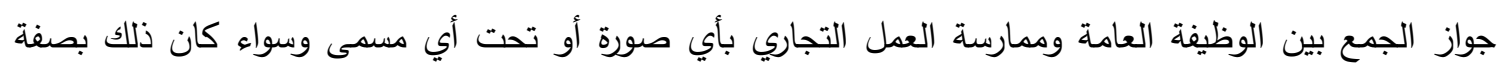

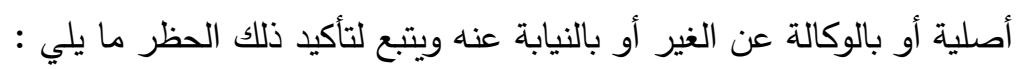

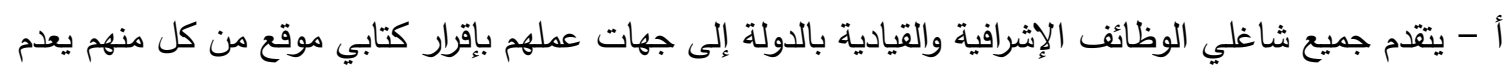

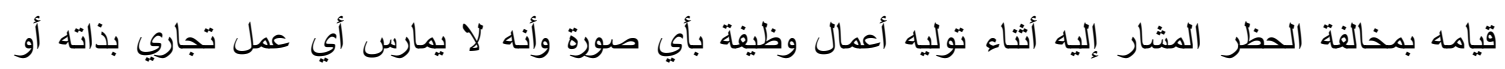
بالتوكيل عن الغير أو نيابة عنه. ب- تقوم الوزارات والجهات الحكومية بموافاة وزارة العدل ووزارة التجارة والصناعة بأسماء جميع العاملين الثاغلين لوظائف إثرافية أو قيادية لديها دوريا في الثهر الأول من كل عام وتقوم الوزارتان بإخطار جهة العمل بأي توكيل

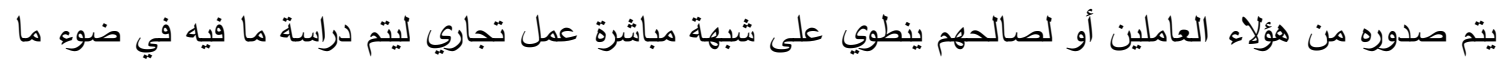
تقدم وفي حالة ثبوت ممارسة التجارة بموجبه يتم اتخاذ الإجراءات التأديبية المقررة .

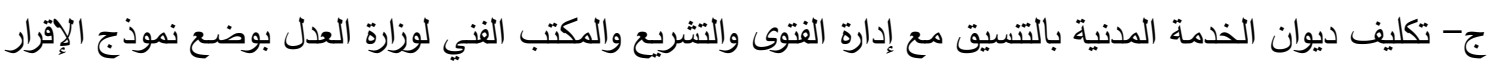
المشار إليه .

2- التأكيد على التزام جميع العاملين في الأجهزة الحكومية بحكم المادة ( 25/ فقرة 3) من قانون الخدمة المدنية الذي يحظر العمل لاى أي جهة أخرى إلا بإذن من الوزير المختص وإلا عد ذلك مخالفة تأديبية تستوجب الإنداء المساءلة

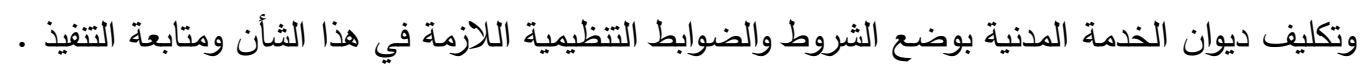
عملا على تثجيع الإبلاغ عن جرائم الفساد يتم التالي: (الكويت، وزارة العدل، 2008) 
1- تكليف اللجنة المختصة بوزارة الداخلية بمكافحة جرائم الفساد ( الرشوة / استغلال النفوذ) مع توفير الدعم اللازم

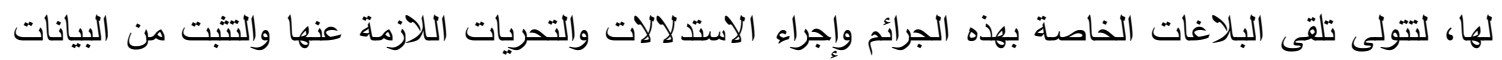

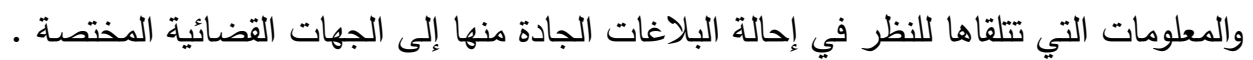

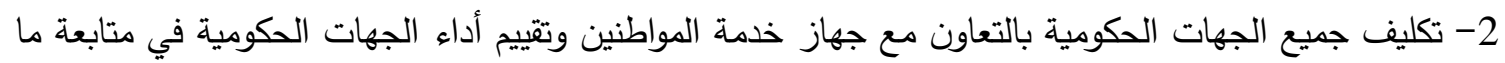
تتخذه الجهات المختصة المشار إليها بالبند (1) من إجراءات في البلاغات والمعلومات التي تتلقاها عن الفساد وما يتخذ حيالها من إجراءات تأديبية أو جزائية ضد من يثبت عليه ارتكاب فساد وظيفي أيا كان موقعه وذلك كله مع في التهات عدم الإخلال باختصاص الجهات المعنية في التصرف في الوقائع والمعلومات حول الفساد بما في ذلك الك توجيه

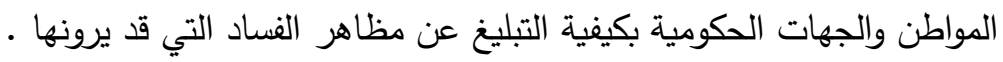
3- تكليف وزارة الإعلام بالتعاون مع الجهات الأخرى ذات الصلة للقيان بحملة إعلامية تستهدف التعريف بخطورة

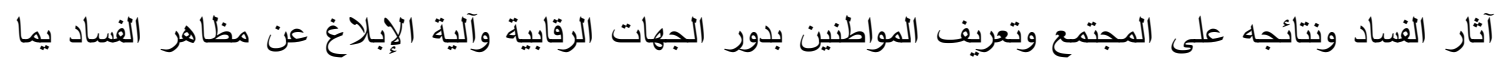
يؤكد جدية الحكومة في محاربة الفساد والقضاء عليه وتكليف وزارة المالية بتوفير الاعتماد المالية اللازمة لهذا لهات الغرض • وفي ذات الثأن وفي 22 أكتوبر 2007 أصدر مجلس الوزراء قراره رقم (1003/2) الذي قضى بتكليف ولفئ وزير المالية بالتوقيع على اتفاقية خدمات استثارية مع البنك الدولي للاعمار والتتمية، وذلك نيابة عن حكومة دولة

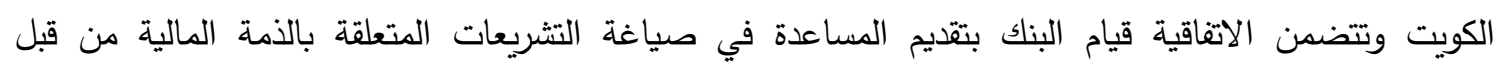

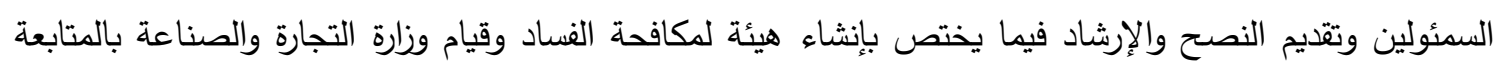
والتتسيق لتنفيذ هذا المشروع مع البنك بالتعاون مع الجمعية الاقتصادية الكويتية -إحدى منظمات المجتمع المدني

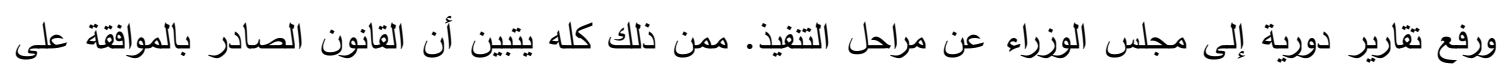

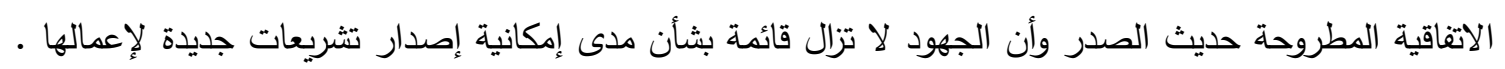

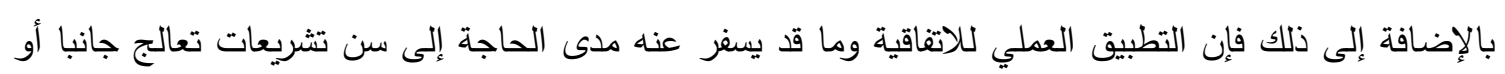

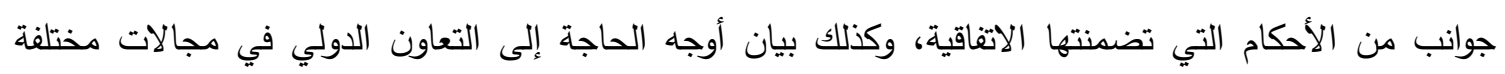
ومتصلة .

وتجدر الإشارة إلى أن ما سبق عرضه يدخل في دائرة اختصاص الكثير من الوزارات والجهات ومن بينها وزارة

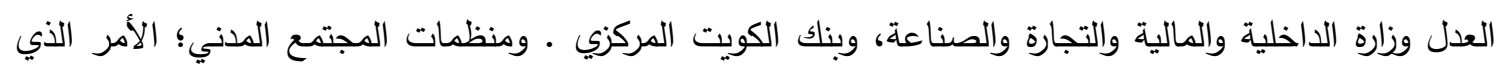
يستلزم تضافر جهود هذه الجهات ؛ في الثأن المطروح وذلك استكمالاً للطرح وتحقيق الأغراض المنشودة ـ وأخيرا

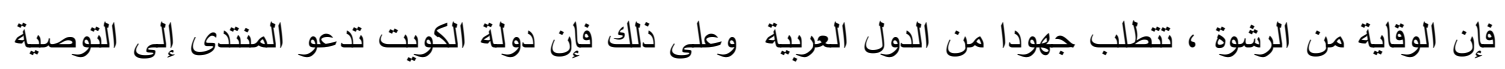
بالآتي: (إدريس، 2019) 1 - 1 - بلى المستوى الدولي

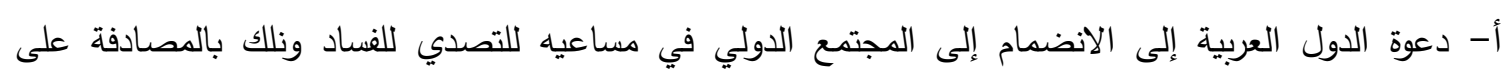

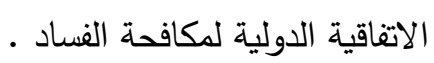

ب- دعوة الدول العربية التي صادقت على الاتفاقية الدولية لمكافحة الفساد متابعة تتفيذها من خلال المشاركة الفاعلة في مؤتمر الدول الأطراف الثالث المزمع عقده بدولة قطر في نهاية 2009 للخروج بقرارات تساهم وتدعم تلقي الدول العربية المساعدة التقنية اللازمة التي تحتاجها من المنظمة الدولية . 2- على المستوى العربي : دعزي أ- دعوة جامعة الدول العربية بإنشاء جهاز متابعة خاص يلحق بالأمانة الفنية لمجلس وزراء العدل العربي مهمته تجميع التطبيقات الوطنية العربية في مكافحة الفساد حتى يكون مرجعا لأحدث ما توصلت إليه هذه الدول من آليات 
ووسائل وأدوات لمحارية هذه الآفة، وذلك من أجل أن يتحقق للتعاون العربي الوثيق اهدافه المرجوة في هذا الميدان

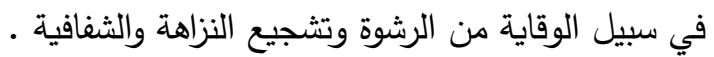
ب- دعوة جامعة الدول العربية إلى ضرورة الانتهاء من إيرام الاتفاقية العربية لمكافحة الفساد على غرار الاتفاقية الدولية . 3-دعوة جامعة الدول العربية إلى ضرورة الانتهاء من إعداد القانون العربي الموحد لـكافحة الفساد وذلك لمساعدة الدول العربية للاسترشاد به في سن التشريعات الملائمة لمكافحة جرائم الفساد بشكل عام والرشوة على وجه الخصوص . 3- على المستوى الوطني :- دعم: أ- دعوة الدول لوضع التدابير التشريعية والإدارية الملائمة لتجسيد مبدأ سيادة القانون وحسن إدارة الثؤون والممتلكات العمومية والنزاهة والثفافية والمساءلة من خلال مراجعة القوانين واللوائح والأنظمة القائمة وسد الثغرات القانونية- إن وجدت - بشأن النظام المالي والإداري ( نظم المشتريات العمومية - والرقابة ) .

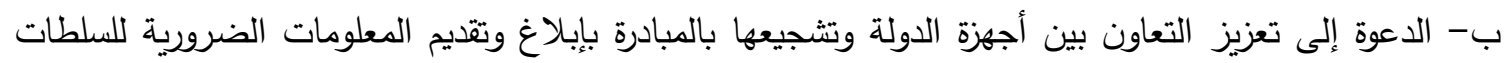

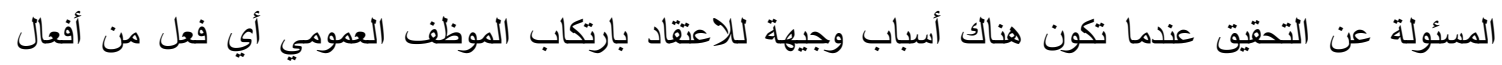
الفساد . (الف ج- دعوة الدول على إشراك منظمات المجتمع المدني في وضع وتتفيذ أو ترسيخ سياسات فعالة منسقة لمكافحة الفساد. ثانيا: عرض للتقارير المحلية والدولية ومناقشتها التي تتعلق بمستويات الفساد المالي بدولة الكويت وما نتج عنه من آثار على النمو الاقتصادي في البلاد وذلك خلال الفترة الممتدة من 2003 إلى 2019 بعد مرور 5 سنوات من الإجراءات الحكومية في تحقيق النزاهة ومكافحة الفساد، استطاعت الكويت الققز من قاع مؤشر (نزاهة الدفاع الحكومي) لتصعد درجة واحدة وتستقر في المرتبة (E) أي (عالي جدا) كما موضوح في الثكل التالي: - ne

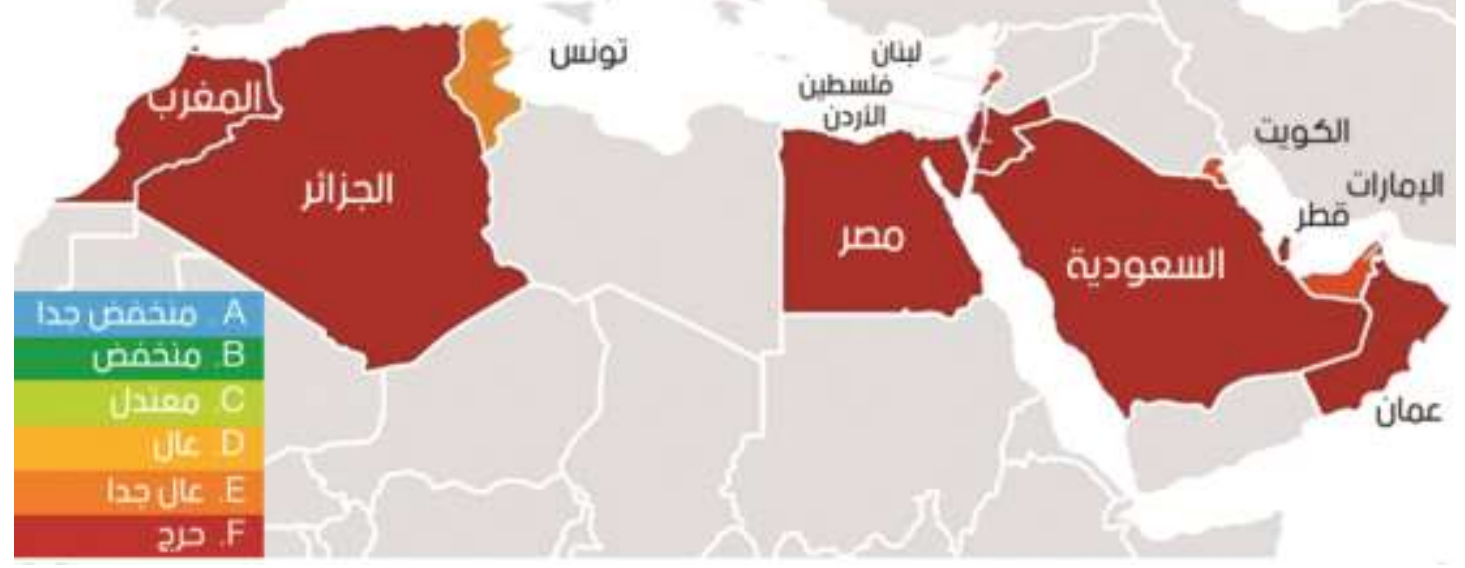

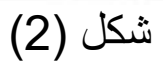

خريطة تبين واقع الدول العربية بشكل عام ودولة الكويت بشكل خاص التي توافرت عنها معلومات في مؤشر الفساد

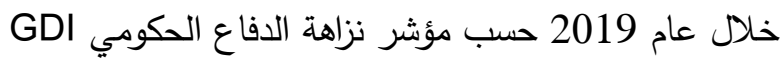
(تقرير الثال الاقتصادية لسنة 2019، ص 35) 
فالكويت دخلت تصنيفا جديدا مع 3 دول عربية، هي لبنان وفلسطين والامارات بعد أن تتفست الصعداء، بالخروج

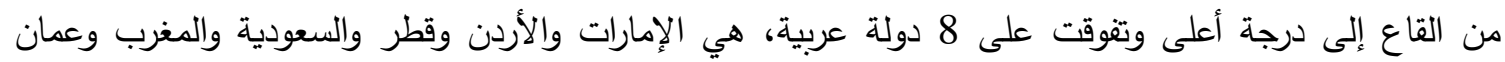

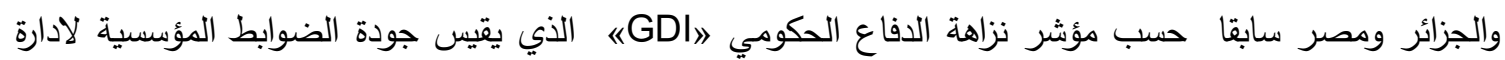

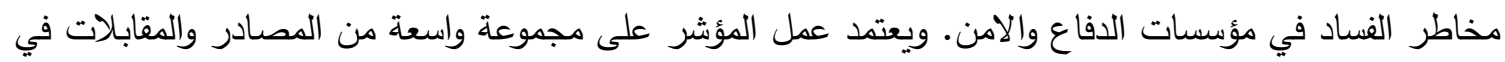

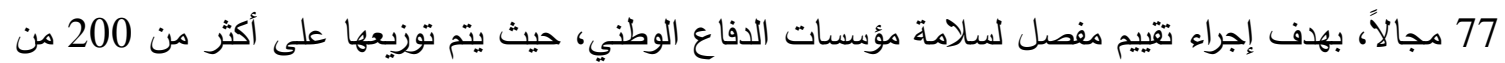
المؤشرات الاساسية التي تحدد نطاق الاستفسار في 5 مجالات رئيسية لخطر الفساد: المخاطر السياسية، مخاطرة مالية، مخاطر الموظفين، مخاطر العمليات ومخاطر المشتريات. وخص التقرير مؤشر نزاهة الكويت بالشرح والتفصيل، تحت عنوان فرعي 》انظرة عامة للكويته، مشيرا إلى أن المتغيرات الجيوسياسية التي تثهدها المنطقة، فاقمت التوترات بين دول الخليج وإيران، فضلاً عن الخلاف الديبلوماسي بين ما أسماه التقرير (بعض جيران آنسير الكويت وقطر) ويقصد هنا الازمة الخليجية، كل ذلك أثار اهتماماً لدى الكويت لتحسين آليات مكافحة الفساد في هياكل الدولة. وأثشار التقرير إلى أن القدرات الدفاعية للكويت أقل من الدول الاخرى في المنطقة نظراً لان وضعها الأمني

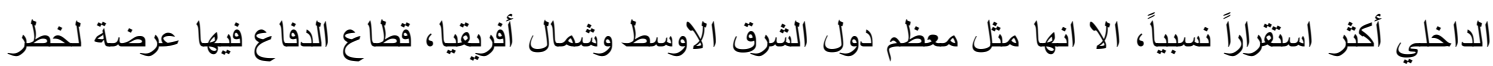
الفساد (جريدة الراي الكويتية، 2019) يلاحظ من خلال الجدول (2) التالي احتلال دولة الكويت المرتبة الأولى خليجيا والخامسة عربيا متقدمة مرتبتين لتحتل المركز الـ 114 عالميا من اصل 167 وذلك ضمن مؤشر الديموقراطية العالمي 2019 الذي تعده سنويا مجلة 》ايكونوميست شالبريطانية.

جدول (2)

دولة الكويت في مؤشر الفساد خلال الفترة من سنة 2003 إلى 2019

\begin{tabular}{|c|c|c|c|c|}
\hline الترتيب خليجيا & الترتيب عالميا & الترتيب6 دوليا & الدرجة من 100 & السنوات \\
\hline 4 & 4 & 35 & 53 & 2003 \\
\hline 5 & 7 & 44 & 46 & 2004 \\
\hline 5 & 7 & 45 & 47 & 2005 \\
\hline 5 & 6 & 46 & 48 & 2006 \\
\hline 5 & 6 & 60 & 43 & 2007 \\
\hline 5 & 7 & 65 & 43 & 2008 \\
\hline 6 & 8 & 66 & 41 & 2009 \\
\hline 6 & 7 & 54 & 45 & 2010 \\
\hline 5 & 5 & 54 & 45 & 2011 \\
\hline 6 & 6 & 66 & 44 & 2012 \\
\hline 6 & 7 & 69 & 43 & 2013 \\
\hline 6 & 7 & 67 & 44 & 2014 \\
\hline 5 & 6 & 55 & 49 & 2015 \\
\hline 6 & 7 & 75 & 41 & 2016 \\
\hline
\end{tabular}




\begin{tabular}{|l|l|l|l|l|}
\hline 5 & 8 & 85 & 39 & 2017 \\
\hline 5 & 8 & 78 & 41 & 2018 \\
\hline 6 & 9 & 85 & 40 & 2019 \\
\hline
\end{tabular}

(جريدة الأنباء الكويتية، 2020)

\section{ويستتتج الباحث بناء على ما ورد من بيانات في الجدول السابق ما يلي: -}

1 - البطء الثديد في تتفيذ اتفاقية الأمم المتحدة لمكافحة الفساد التي انضدت لهاهي الكويت في 2003 وصادق عليها مجلس الأمة في 2006، فما زالت العديد من الالتزامات الدولية لم يتم بشأنها شيء مثل التصدي لتفشي لتعادي ظاهرة تعارض المصالح. 2- - ضعف الثفافية وعدم سهولة الوصول إلى المعلومات. 3- تقشي الواسطة وغياب نظم ومعايير الكفاءة والجدارة في الترقيات واختيار المسؤولين والقيادات وتقييمهم والتجديد لهم.

4- تفشي البيروقراطية في المعاملات الحكومية وطول الدورة المستندية وضعف نظم الحكومة الإكترونية. 5- بطء تتفيذ العدالة بشكل لافت لدى كل من النيابة العامة والقضاء، وتأخر البت في قضايا الفساد الإداري وانتهاك المال العام 6- ضعف المساءلة وخاصة فيما تسفر عنه التقارير الرقابية الصادرة عن الأجهزة الرقابية. 7- التضييق على منظمات المجتمع المدني وتراجع دورها بشكل كبير في تعزيز المساءلة المجتمعية.

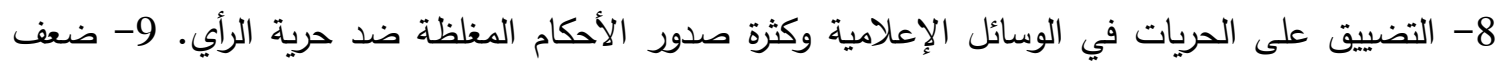
الآليات التي تثجع الناس على المشاركة في الاختيار والرقابة على الأداء البرلماني والنقص في النّام النظم المتعلقة

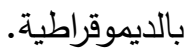
10 - مازالت نظم الإدارة المالية للدولة ومشترياتها ضعيفة وتحتاج إلى تطوير، حيث تغيب آليات صحيحة لاختيار المسؤولين عن تلك الإدارة، وآليات الرقابة والتقييم والتجديد وإدارة المخاطر . 11- ضعف تطبيقات الحوكمة، وضعف نظم إدارة المخاطر في القطاع العام، وعدم تفعيل تطبيق القوانين. 12 - تأخر تنفيذ استراتيجية الكويت لتعزيز النزاهة ومكافحة الفساد 2019 ـ 2024. 13- أن الكويت، ربما تكون البلد الوحيد، الذي ترتفع فيه تكلفة أجهزة مكافحة الفساد البشرية والمالية، في الوقت الذي تتصاعد فيه تكلفة الفساد بمعدلات أسرع، والأسوأ، هو عدم قيام جهة حكومية بنفي ما ينسب لها من اعترافها بغياب أي إستراتيجية لمواجهة الفساد، ذلك يعني غياب أي سياسة وقائية تحد من إستشرائه. 
جدول (3)

ترتيب دولة الكويت في العامين الماضيين 2018- 2019

\begin{tabular}{|c|c|c|c|c|c|c|c|}
\hline \multicolumn{3}{|c|}{2019} & \multirow[b]{2}{*}{ بصن } & \multicolumn{3}{|c|}{2018} & \multirow[b]{2}{*}{ ترتيبي الديرة } \\
\hline من 100 & حتريبي & دوبيا & & عن 100 & متربيا & دوبي المتبي & \\
\hline 71 & 1 & 21 & $1+$ & 70 & 1 & 23 & 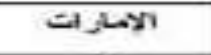 \\
\hline 62 & 2 & 30 & - & 62 & 2 & 33 & fol \\
\hline 53 & 3 & 51 & $4+$ & 49 & 4 & 58 & 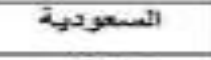 \\
\hline 52 & 4 & 56 & $=$ & 52 & 3 & 53 & on \\
\hline 48 & 5 & 60 & 1- & 49 & 4 & 58 & an \\
\hline 43 & 6 & 74 & - & 43 & 6 & 73 & تصتصن \\
\hline 42 & 7 & 77 & $6+$ & 36 & 9 & 99 & الهحريت \\
\hline 41 & 8 & $\mathbf{s o}$ & $2-$ & 43 & 6 & 73 & كلرب \\
\hline 46 & 9 & 85 & $1-$ & 41 & 8 & 78 & $5+509$ \\
\hline 35 & 10 & 106 & $=$ & 35 & 10 & 105 & لجيز لر \\
\hline 35 & 10 & 106 & - & 35 & 10 & 105 & rar \\
\hline 30 & 12 & 126 & $1-$ & 31 & 12 & 124 & جيشت \\
\hline 28 & 13 & 1.37 & - & 28 & 13 & 138 & لبتاد \\
\hline 28 & 13 & 137 & $1+$ & 27 & 14 & 14.4 & مدينتبا \\
\hline 25 & 15 & 153 & $2-$ & 27 & 14 & 144 & 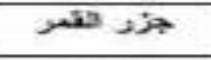 \\
\hline 20 & 16 & 162 & $2+$ & 18 & 16 & 168 & 30 \\
\hline 18 & 17 & 168 & $1+$ & 17 & 17 & 170 & تيبي \\
\hline 16 & 18 & 173 & $=$ & 16 & 18 & 172 & تسودان \\
\hline 15 & 19 & 177 & $1+$ & 14 & 19 & 176 & اليجيمث \\
\hline 13 & 20 & 178 & $=$ & 13 & 20 & 178 & 4200 \\
\hline 9 & 21 & 180 & 1- & 10 & 21 & 180 & 3 \\
\hline
\end{tabular}

(تقرير منظمة الثفافية الدولية لسنة 2019).

ملاحظة: درجة صفر تثير إلى فاسد جدا، ودرجة (100) تشير إلى نظيف جدا.

لقد حلت الكويت في المركز الـ 85 عالميا من بين 180 دولة في مؤشر مدركات الفساد العالمي الذي تصدره منظمة الشفافية الدولية متراجعة بذلك سبع مراكز بعدما كانت تحتل المركز الـ78 عالميا العام 2018. وحصلت الكويت على 40 نقطة من أصل مئة نقطة ويعزى هذا التراجع الى تأخر صدور جملة من التشريعات وتواتر أخبار قضايا الفساد. إن مؤشر مدركات الفساد يصدر سنويا منذ العام 1995 من قبل المنظمة ومركزها برلين ويحدد مستوى تفشي الفساد في القطاع العام بثقيه السياسي والإداري، معتمدا على مدركات أو انطباعات انتشار الفساد من خلال مقياس مركب لاستطلاعات رأي رجال الأعمال والتتفيذيين الاشرافيين في القطاع الخاص وتقييم الخبراء الأجانب والمحليين. ويعتمد المؤشر على 13 مصدراً للمعلومات تصدر من مؤسسات عالمية متخصصة ومستقلة ويرصد كل مصدر نتيجة كل دولة في جوانب محددة من الفساد، والتي تتحصر في احدى

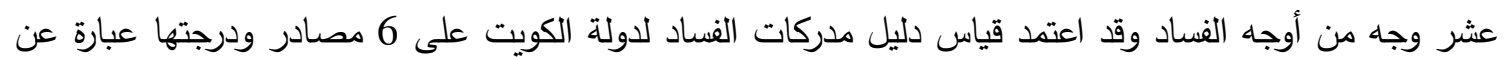
متوسط حسابي لدرجتها في تلك المصادر الـ 6. إن منظمة الثفافية الدولية أصدرت تقرير مؤشر مدركات الفساد 
للعام 2019، إذ حصلت الكويت على درجة (40) بانخفاض درجة واحدة عن درجتها عام 2018 إذ جاء ترتيبها

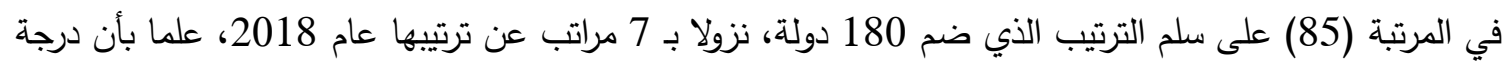

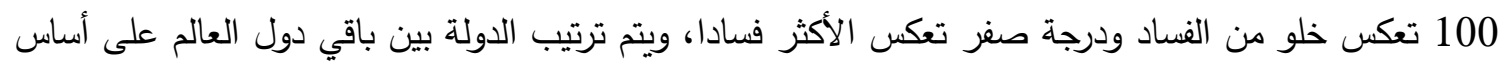
تسلسلي وليس بالضرورة بمقدار تقدم أو تأخر درجتها. حيث يتبين من قراءة نتائج دولة الكويت وفقا لنتائج المصادر

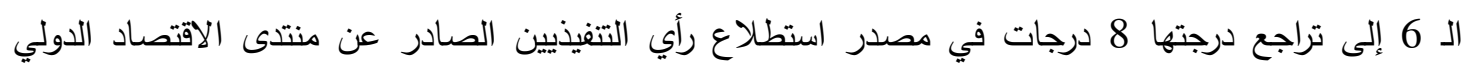

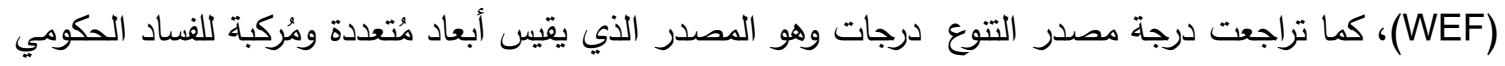
والتشريعي والقضائي. ومن جهة أخرى فانه لم يطرأ أي تغيير على درجة الكويت في كل من مصدر التهار دليل المخاطر

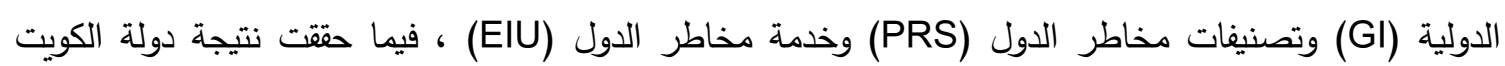
ارتفاعا ملحوظا في مصدر دليل بيرتلمسان للتحول (BF) الذي يقيس محاكمة أو معاقبة أصحاب المناصب العامة من الفاسدين والمتجاوزين على القانون بصرامة وفقاً للقوانين، وكذلك مدى نجاح الحكومة في احتواء الفساد، ووجود أدوات فاعلة تضمن الاستقامة. وتجدر الإشارة إلى أن منظمة الثفافية لا تقدم تحليلا خاصا لنتيجة دولة الكويت ولذلك فإن تراجع درجة الكويت سببه عدة أسباب نستقرئ أبرزها تأخر صدور جملة من التشريعات القانونية، التي التئي

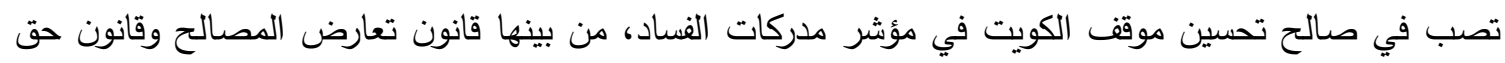
الاطلاع وتتظيم الحصول على المعلومات، وقانون تنظيم تعيين القياديين وقانون تتظيم تمويل الحملات الانتخابية،

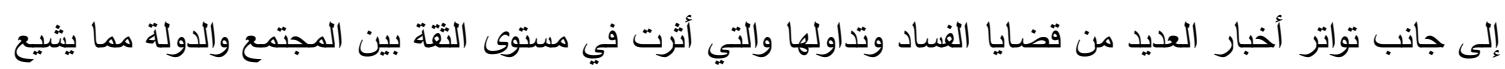
الانطباع إلى عدم انفاذ القانون في تطبيق الأحكام على الفاسدين واسترداد الأموال حسب توصيات منظمة التئ الثفافية الدولية. إضافة إلى سرعة الانتهاء من بعض التشريعات المقترحة ومنها قانون الجزاء بغية جعل الرشوة للموظفين

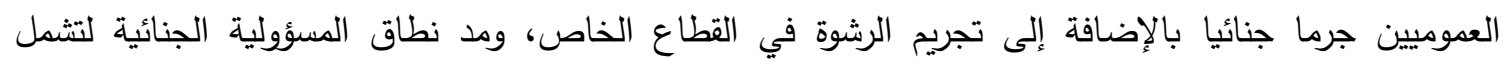
الأشخاص الاعتباريين وذلك مواكبة للاتفاقيات والمعاهدات الدولية المتعلقة بتطوير التدابير اللازمة للوقاية من فئل الفساد (جريدة الراي الكويتية، 2020). وفي تقرير أصدرته الثال الاقتصادية ، فقد أشار إلى وجود 42 ألف قضية خاصة لسرقات المال العام فقط،

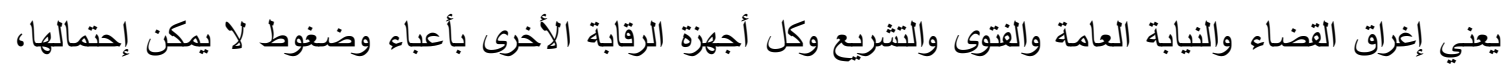

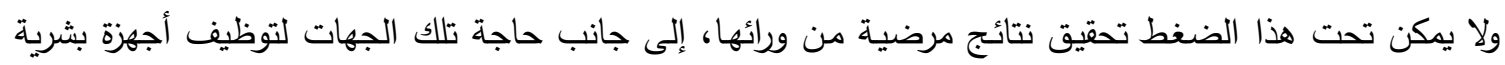

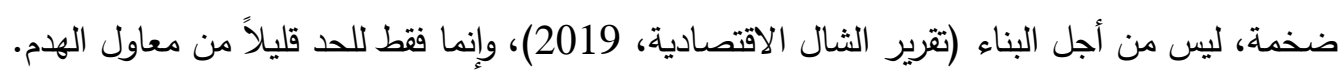
ويرى الباحث بأن تكاليف وباء الفساد ليست أهمها الخسائر المالية، وإنما سقوط كل ماعداه من مؤشرات مثل فئل

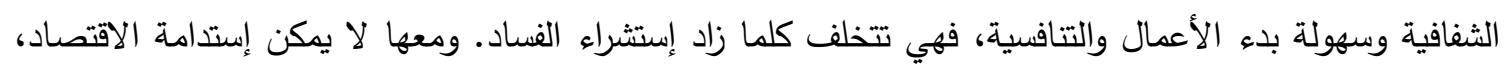

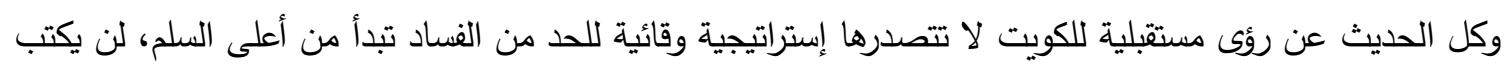
لها النجاح، وتلك حالة مثبتة في تجارب النهوض حول العالم. لقد أصبحت القاعدة هي أن تتخلف الكويت الجميلة

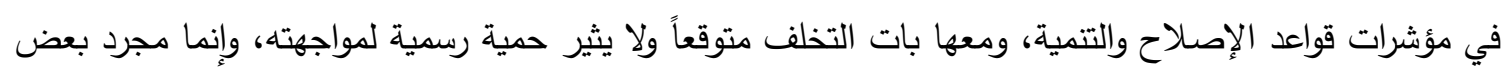
الإنتظار حتى يزول زخمه، وذلك لا يحقق إستدامة ولا تنمية إلا من خلال اتباع سياسة أخرى قائمة بالعودة إلى ولى ولى التشريع الإسلامي وقوانينه. 
تتقرير الاتجاهات الاسترتيجية". (2005). القاهرة: مركز الدراسات السياسية والاستراتيجية بالأهرام. ادريس، عبد الفتاح محمود. (2013). "مكافحة شائبة الفساد الإداري في المجتمعات المعاصرة: دراسة مقارنة بين القانون الوضعي والثريعة الإسلامية" ، مجلة البحوث والدراسات الثرعية ، المجلد الثالث والعشرين، العدد

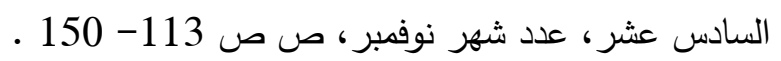

بحار، محمد (2016). "الإطار القانوني لمحاربة الفساد: قراءة في إتفاقية الأمم المتحدة لمحاربة الفساد

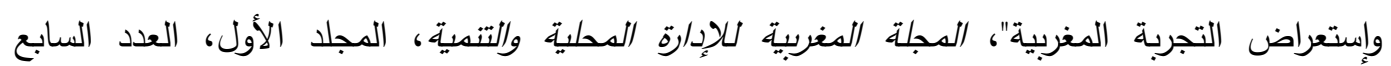

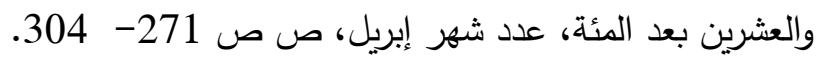

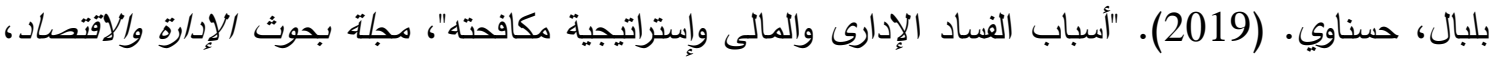

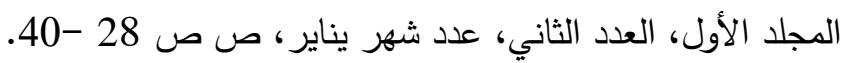

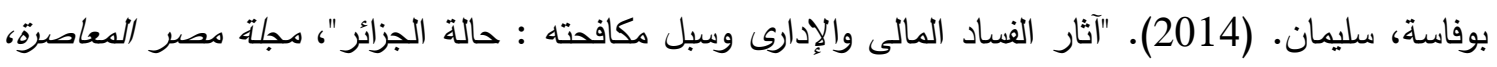
الجدعية الدصرية للاقتصاد السياسي والإحصاء والتشريع، المجلد الخامس بعد المئة، العدد الثالث عشر الثرانه

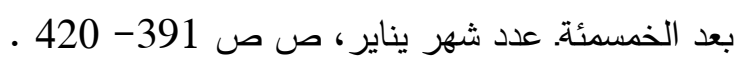

جريدة الأنباء الكويتية. (2020). صفحة أخبار الكويت بعنوان: " الكوبت الأخيرة خليجياً والتاسعة عربيًا ببؤشر

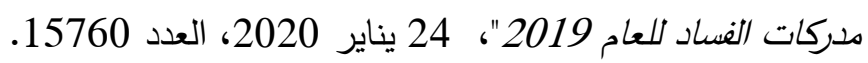

حنا، يوسف، صابر • (2016). "لماذا يزداد الفاسدون: قراءة في مؤشر الثفافية الدولية"، مجلة السياسة الدولية، السنة الثانية والخمسين، ملحق، عدد شهر إبريل، ص ص ص 25 - 25 -30.

الرفاعي، سلامة بن سليم. (2015). الهيئة الوطنية لمكافحة الفساد ودورها في محاربة الفساد: دراسة مقارنة"، الرياض: مكتبة القانون والاقتصاد.

سهيلة، عبد الزهراء. (2015). "الفساد الإداري والمالي في العراق: مظاهر وأسباب ومعالجات"، مجلة الإدارة

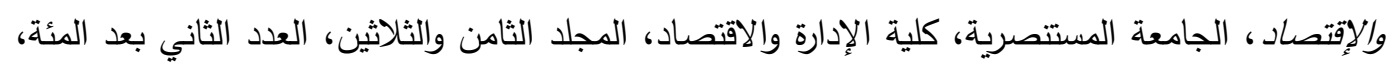

$$
\text { عدد شهر مايو، ص ص صل 49-61. }
$$

الثريف، محمد بن عبد الله. (2016). "النزاهة في مواجهة الفساد: تجربة المملكة العببية السعودية"، الرياض: دار

$$
\text { العبيكان للنشر والتوزيع. }
$$

شمري، هاشم محمد. (2011). "الفساد العالي والإداري وآثاره الاقتصادية والاجتماعية"، بيروت: دار اليازوري

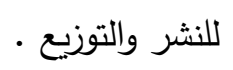

عبود، علي سكر • (2010). "تحليل صور وأسباب الفساد المالي والإداري : دراسة استطلاعية لعينة مختارة في

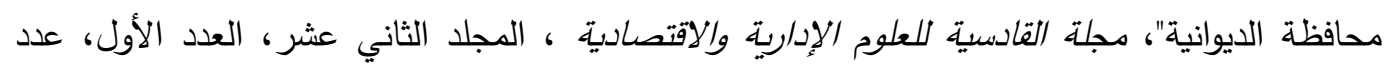

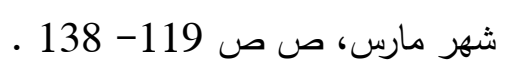

القرطبي، محمد بن أحمد. (2005). الجامع لأحكام القرآن"، القاهرة: دار الحديث للنشر والتوزيع.

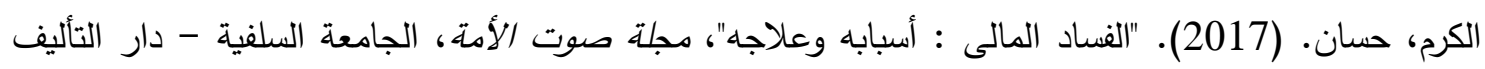

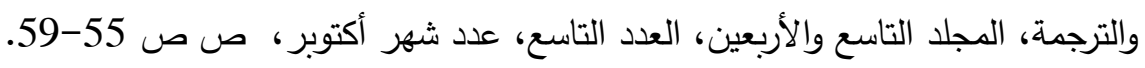

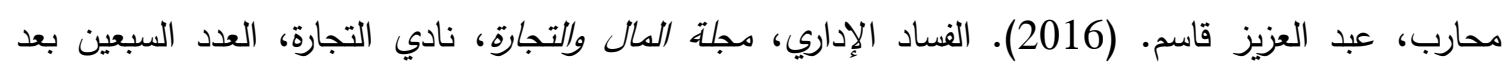

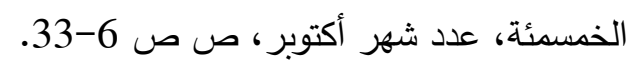




$$
\begin{aligned}
& \text { معتوق، سامية محمد. (2019). "الفساد في الدول العربية: بين مصاعب الواقع وحتمية المعالجة"، مجلة دراسات }
\end{aligned}
$$

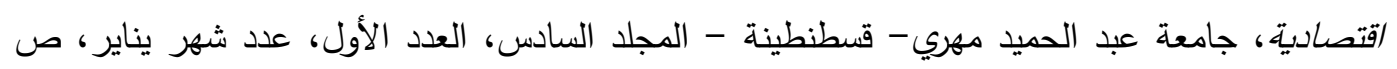

$$
\begin{aligned}
& \text { ص } 247 \text {-270 . } \\
& \text { يونس، حنان أحمد. (2016). "آليات مكافحة الفساد الإدارى والمالى"، مجلة العدل، دولة الكويت / وزارة العدل، }
\end{aligned}
$$

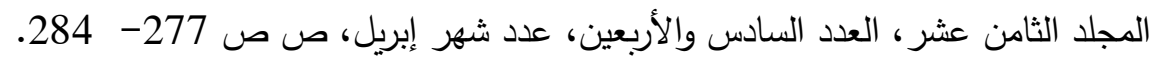

\section{References}

Abboud, Ali Sukkar. (2010). Analysis of pictures and causes of financial and administrative corruption: An exploratory study of a selected sample in the province of Diwaniyah. Al-Qadisiyah Journal of Administrative and Economic Sciences, 12(1), 119-138. (in Arabic)

Ackerman, S. (2011). Corruption and other political pathologies, The Encyclopedia of Political Science, Washigton, D C: CQ Press

Alareeni, B., Qdeh, N., \& Lulu, M. (2018). Determinants of Inflation in Palestine. International Journal of Business Ethics and Governance, 1(3), 68-93. https://doi.org/10.51325/ijbeg.v1i3.43

Alexander, C. \& Cumming, D. (2020). Corruption and Fraud in financial markets: Malpractice, Misconduct and Manipulation, New York: John Wiley \& Sons.

Alkaram, Hassan. (2017). Financial Corruption: Its Causes and Cure, Sawt Al-Ummah magazine, 49(9), 55- 59. (in Arabic)

Alqallaf, H. and Alareeni, B. (2018). Evolving of Selected Integrated Reporting Capitals among Listed Bahraini Banks, International Journal of Business Ethics and Governance, 1(1), pp. 15-36. https://doi.org/10.51325/ijbeg.v1i1.10

Al-Qurtubi, Muhammad bin Ahmed. (2005). Al-Jami 'for the provisions of the Qur'an, Cairo: Dar al-Hadith for publication and distribution. (in Arabic)

Al-Rifai, Salama Bin Sulayem. (2015). The National Anti-Corruption Commission and Its Role in Fighting Corruption: A Comparative Study, Riyadh: Law and Economics Library. (in Arabic)

Bilbal, Hasnawi. (2019). Administrative and financial corruption causes and a strategy to combat it. Journal of Management and Economics Research, 1(2), 28-40. (in Arabic)

Boufasa, Suleiman. (2014). The Effects of financial and administrative corruption and ways to combat it: the case of Algeria. Journal of Contemporary Egypt, (150), 391-420. (in Arabic)

Brooks, G. Walsh, D. \& Lewis, C. (2013). Preventing corruption investigation, enforcement and governance, England: Palgrave MacMillan. https://doi.org/10.1057/9781137023865

Ertimi, B. Abdelkasem, D. Albisht, E. \& Oqab, B. (2016). The Impact of Corruption on Economic Growth in OIC Countries, International Journal of Economics and Finance, 8(9), 91- 103. https://doi.org/10.5539/ijef.v8n9p91

Hanna, Youssef, Saber. (2016). Why are corrupt people increasing: a reading in transparency international index, Al-Siyasa Al-Dawlia, Fifty-second year, supplement, (April), 25-30. (in Arabic)

Healey, J. (2015). Corruption, Australia: Spinney Press. 
Ibrahim, T. (2019). The legitimate aspects of corruption and the strategy of its combat to enhance the justice values. Rule of Law and Anti-Corruption Center Journal, 1(4), 92- 115.

Idris, Abdel Fattah Mahmoud. (2013). Combating the defect of administrative corruption in contemporary societies: a comparative study between positive law and Islamic law. Journal of Research and Sharia Studies, 23(16), 113-150. (in Arabic)

Kuwaiti Al-Anbaa Newspaper. (2020). Kuwait News Page Entitled: Kuwait is the last in the Gulf and the ninth in the Arab world in the Corruption Perceptions Index for the year 2019, 24(15760). (in Arabic)

Maatouk, Samia Mohamed. (2019). Corruption in the Arab countries: between reality difficulties and the inevitability of treatment. Journal of Economic Studies, 6(1), 247-270. (in Arabic)

Mendilow, J. \& Peleg, I. (2016). Corruption and governmental legitimacy: a twenty first century perspective, The United States: Lexington Books.

Mevliyar, E. (2012). Corruption from the Islamic Perspective: Some Recommendations for the MENA. International Journal of Islamic and Middle Eastern Finance and Management, 1(1), 31- 51. https://doi.org/10.1108/17538390810864241

Moharib, Abdul Aziz Qasim. (2016). Administrative corruption. Journal of Finance and Trade, (70), 6-33. (in Arabic)

Sailor, Muhammad. (2016). The legal framework for fighting corruption: a reading in the United Nations Convention against corruption and a review of the Moroccan experience. The Moroccan Journal of Local Administration and Development, 1(127), 271- 304. (in Arabic)

Shamri, Hashem Muhammad. (2011). Financial and administrative corruption and its economic and social effects. Beirut: Al-Yazouri House for Publishing and Distribution. (in Arabic)

Sharif, Mohammed bin Abdullah. (2016). Integrity in the face of corruption: the experience of the Kingdom of Saudi Arabia, Riyadh: Al-Obeikan Publishing and Distribution House. (in Arabic)

Strategic Directions Report. (2005). Cairo: Al-Ahram Center of Political and Strategic Studies. (in Arabic)

Suhaila, Abdul Zahra. (2015). Administrative and financial corruption in Iraq: Manifestations, causes and treatments. Journal of Management and Economics, 38(102), 49-61. (in Arabic)

Yunus, Hanan Ahmed. (2016). Mechanisms to combat administrative and financial corruption. Justice Magazine, 18(46), 277-284. (in Arabic) 